\title{
Pursuing Chemical Efficiency by Using Supported Organocatalysts for Asymmetric Reactions under Aqueous Conditions.
}

\author{
Gabriela Guillena*, Diego Alonso, Alejandro Baeza, Rafael Chinchilla, Jesús Flores-Ferrándiz, \\ Melania Gómez-Martínez and Paz Trillo.
}

Departamento de Química Orgánica and Instituto de Síntesis Orgánica, Universidad de Alicante, Apdo. 99, E-03080 Alicante, Spain.

\begin{abstract}
Over the past decade, a great effort has been made by the chemical community to improve the efficiency and greenness of reactions. Merging the use of supported and recyclable organocatalysts and aqueous conditions to pursue this goal in the asymmetric synthesis of interesting enantioselective molecules lead to outstanding results in some cases. Progresses in this area also offer the possibility of having even more sustainable processes by implementing these reactions in the large scale production of chiral molecules using automated flow chemistry.
\end{abstract}

Keywords: immobilization, enantioselective, aqueous, polymers, ionic liquids, dendrimers, flow chemistry, organocatalysis.

\section{INTRODUCTION}

In words of R. Noyori, 'chemists must pursue practical elegance," by the development of more efficient and sustainable processes, catalysis being one of the ways to achieve this goal [1]. In Nature, this chemical efficiency is wonderfully illustrated by the action of enzymes [2], that selectively convert rather small building blocks into sophisticated molecular architectures which ruled physiological processes in living organisms. These enzyme catalyzed biotransfomations are generally performed in water, with the reaction taking place in a hydrophobic pocket of the enzyme. The use of water as solvent to carry out any transformation [3] meets several criteria of what it is known as 'green chemistry' $[4,5]$. Thus, water has several important advantages: a) is abundant, and therefore cheap; b) is safe, because is non-flammable and nontoxic; c) is environmentally friendly and renewable; d) is convenient from a practical point of view, as there is no need of using dry solvents and glassware. In addition, water has unique chemical and physical properties such as its hydrogen bonding ability and high density, surface tension and cohesive energy density, which may affect the evolution of a chemical process. Conversely to what happens in Nature with enzymes, in catalytic asymmetric organic synthesis $[6,7]$ it is well established that the use of water may disrupt hydrogen bonding and polar interactions between catalyst and substrates, therefore having a deleterious effect in the stereoselectivity of the reaction $[8,9]$.

Trying to mimic the catalytic action of the selective enzymes, over the last decade, small organic molecules have been successfully used as promoters for several enantioselective organic transformations [10-13]. This type of methodology, known as organocatalysis, has become the third pillar of asymmetric catalysis, together with biocatalysis and transition-metal catalyzed processes. Organocatalysts are tolerant to air and moisture, thus allowing their use under aqueous conditions or in sole water as solvent [14].

However, in organocatalytic transformations, both substrates and catalysts are usually insoluble in water, raising a debate about considering these reactions as 'in water,' 'on water' or 'in the presence of water'. Accordingly to Sharpless, 'on water' reactions are processes that take place in an emulsion, displaying consequently an acceleration rate compared to the same transformation in organic media [15]. Hayashi introduced a differentiation between the 'in water' or 'in the presence of water' terminology for organocatalytic reactions [16]. The first one was attributed to homogeneous dissolved reactants processes, whereas the second one would take place in a concentrated organic media, with water being a second phase influencing the stereochemistry of the achieved products. Simultaneously, the 'green' perspective of such processes was questioned by Blackmond [17], since most of these reactions are carried out in the presence of a great excess of one reagent or by addition of a surfactant/micellar agent. In a strict sense, water can only be considered as a green solvent if it can be directly discharged to a biological effluent plant and the work-up of the reaction has being performed using minimal amounts of an environmentally friendly organic solvent.

Nevertheless, the replacement of organic solvents by water can always be recognized as a development in the greenness of the reaction, especially if the activity of the catalysts is enhanced $[18,19]$. For organocatalytic systems, the beneficial effect of water is mainly due to two reasons: 
firstly, water reduces side reactions, such as the formation of iminium ions [20], and secondly, it speeds up the reaction. This last effect in the reaction rate has been theoretically studied [21], showing that 'dangling $\mathrm{OH}$ groups' $(\mathrm{OH}$ groups that are not hydrogen bonded and protrudes in the organic layer) from the interface water-oil form stronger hydrogen bonds with the transition states that with the reactants, thus enhancing the catalytic activity. On the other hand, although the role of water is not clear when a high stereoselectivity is achieved, the key of success is generally due to an increase of the hydrophobicity of the catalysts. This emulates the action of the hydrophobic pocket of the enzymes, therefore leading to a heterogeneous system. However, increasing the hydrophobicity of a catalyst do not provides a practical procedure for its separation from the products, as both would be soluble in the organic phase. Taking into account that the typical catalyst loading in organocatalyzed processes ranges $10-30 \%$ mol, a catalytic design leading to recoverable and recyclable systems would be highly desirable [22,23]. This goal can be accomplished by anchoring them to hydrophobic supports, such as organic or inorganic polymers or dendrimers [24], or even providing them with the correct amphiphilic character through a ion tag strategy [25].

In this review, the development of new supported organocatalytic systems that can be used under aqueous conditions for the enantioselective synthesis of chiral molecules will be discussed. For that purpose, organocatalysts will be presented by reaction and support type: organic polymers, inorganics, dendrimers and ionic liquid immobilized systems, highlighting the advantages of each of the catalytic systems.

\subsection{Aqueous aldol reactions with supported organocatalysts}

The process discovered by Wurtz in 1872 [26] where an enolizable carbonyl compound (acting as nucleophile) reacts with itself or another carbonyl compound (acting as electrophile) affording a $\beta$-hydroxy carbonyl compound, is known as the aldol reaction (Scheme 1) [27]. This useful transformation allows the formation of a C-C bond, with the possible concomitant creation of one or more stereogenic centers [28,29]. In nature, this reaction is catalyzed by aldolase enzymes, which can be of type I, operating via an enamine mechanism, or of type II, working through the formation of an enolate [30]. Both are active in water in a very selective way but with a limitation in the substrate scope. The use of small organic molecules to perform this reaction [30-36] gave the definitive boost for the development of organocatalysis, L-proline (1) and its derivatives being the most used systems to carry out this transformation in an intra- [37-42] or intermolecular fashion $[43,45]$. Although the use of this type of catalysts has several advantages, such as the atom economy enhancement, the use of mild reaction conditions and, more important, the lack of contamination with toxic metals of the final product, generally these organocatalytic systems are used in high loadings (from 10 to $30 \mathrm{~mol} \%$ ) and show their efficiencies in high polar solvents such as DMSO or DMF. However, the proper design of the catalysts has allowed to perform this reaction in a more sustainable way [46], including the application of solvent-free conditions [47] or the use of water as solvent [48]. The addition of water in the proline catalyzed aldol reaction has several effects, such as assisting the hydrolysis of the oxazolidinone intermediate formed by reaction with the aldehyde, ketone or product [49,51], facilitating the hydrolysis of the enamine intermediate in the catalytic cycle and, finally, diminishing the LUMO of the incoming electrophile, which facilitates a proton transfer in the transition state. Thus, the addition of water up to 300 mol\% benefits the process, while the use of a higher amount leads to a racemic product.

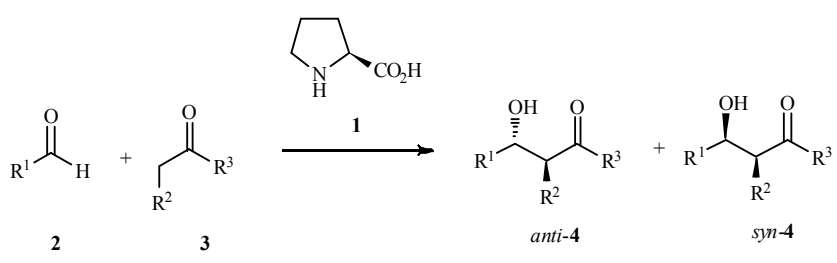

Scheme 1. L-Proline catalyzed intermolecular aldol reaction.

In order to use small molecules as catalysts for the aldol reaction under aqueous conditions, hydrophobic groups have been attached to functional groups of the native catalyst. For instance, Hayashi incorporated an hexanoyloxy group at the 4-position of 4-hydroxy-L-proline, allowing its use in a water/oil emulsion [52] This position of the 4-hydroxy-Lproline has been used to support this molecule to several polymers following different synthetic strategies. For instance, this catalyst has been incorporated to a polystyrene Merrifield resin through a 1,3-dipolar cycloaddition reaction with the corresponding $O$-propargyl hydroxyproline derivative [53,55]. When $10 \mathrm{~mol} \%$ of resin 5 (Figure 1) was used in the aldol reaction between acyclic and cyclic alkyl ketones (3, 5 equiv.) with different aromatic aldehydes in water as reaction media, the expected aldols 4 were achieved with excellent diastereo- and enantioselectivities (64-94\% de, and $93-97 \%$ ee), with the exception of $\alpha$-hydroxyacetone that led to poor results. The addition of poly(ethyleneglycol) dimethyl ether (DiMePEG-2000, $10 \mathrm{~mol} \%$ ) facilitated the diffusion of reagents from the solvent-resin interphase, enhancing the yields (18-97\% yield). The presence of water was compulsory to achieve good results, suggesting that the reaction took place at the interphase between polymer and the aqueous phase. Resin 5 was recovered by filtration and reused three times affording similar results [56]. This resin was also deployed under continuous flow in the presence of organic solvents for other enantioselective transformations [57]. The attachment of the proline moiety directly through the 1,2,3-triazole linker (resin 6, Figure 1) allowed the establishment of a hydrogen-bond-based aqueous microphase around the hydrophobic resin. Supported catalyst $6(10 \mathrm{~mol} \%)$ formed a gel-like single phase in sole water as 
reaction media with an improved activity for the same aldol reaction $(16-99 \%, 68-94 \%$ de, $94-99 \%$ ee) in a shorter reaction time. The catalyst was recovered and reused at least five times affording similar results [58]. When a $p$-phenylene spacer was introduced in the catalytic system (catalyst 7 , Figure 1), the enantioselectivity of the reaction was further increased, probably because the separation between the hydrophilic, catalytically active moiety and the hydrophobic polymer backbone was also increased. In order to achieve higher conversions, catalyst $7(10 \mathrm{~mol} \%)$ was used in a $1: 1$ mixture of DMF:water as solvent, the catalysts being recovered and reused up to seven times under batchconditions. The use of this solvent mixture allowed to apply the catalyst under flow conditions in a packed-bed reactor, with similar results to those obtained under batch conditions. In addition, different aldol products were prepared using the same resin after washing it with DMF, water and cyclohexanone for a small period of time before employing two different aldehydes, which resulted in a high productivity (mmol of product per mmol of resin and hour) in each case[59]. By changing the nature of the resin for polystyrene to polynorbornenes, supported systems of type $\mathbf{5}$ and 6 were obtained using alkyl spacers of different length between the triazol moiety and the resins. These two supported systems were tested as supported catalysts in the aldol reaction between cyclohexanone and several aromatic aldehydes, showing a different behavior. Thus, while catalyst of type $5 \quad(10 \mathrm{~mol} \%)$ afforded the best results in DMSO:water (87:13) in the presence of TFA (10 mol\%), catalyst of type $7(10 \mathrm{~mol} \%)$ led to better results in DMF:water (1:1) in absence of additives. Both catalysts could be recovered after the reaction by filtration and reused for at least seven times. A small decrease in activity was encountered for catalyst 5 due to some leaching of the proline residue, whereas catalyst 7 showed comparable results for each reaction cycle and no leaching at all. The use of the robust polynorbonene resin as support, with a complete saturated structure, transparent to UV light, made these systems suitable candidates to be applied in photoorganocatalyzed reactions[60].

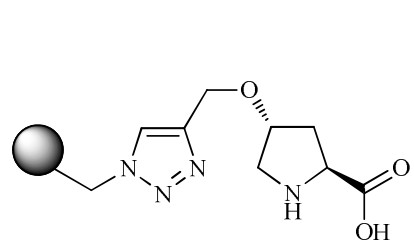

5

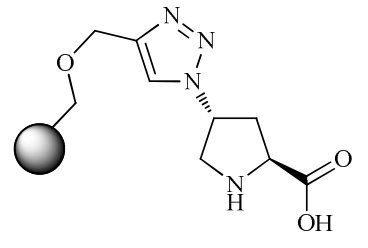

6

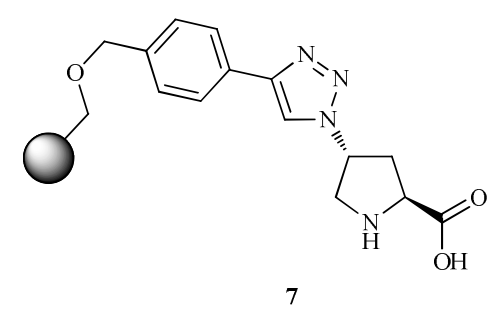

Figure 1. 4-Hydroxy-L-proline derivatives supported using click-chemistry.

Using also a click reaction trans-4-hydroxyproline was grafted to commercially available mercapto-methylpolystyrene resin by means of a thiol-ene reaction, giving catalyst 8 (Figure 2). This polymeric organocatalyst (10 $\operatorname{mol} \%$ ) was used in the aldol reaction between cyclohexanone ( 2 equiv.) with different aromatic aldehydes in a small amount of water as solvent, affording mainly aldols anti-4 in good chemical yields, and excellent diastereo- and enantioselectivities (71-98\%, 84-92\% de, 90$98 \%$ ee) [61,62]. Using other cyclic ketones as nucleophiles, similar results were found, acetone giving low yields. The resin was recovered by simple filtration and reused four-fold achieving reproducible enantioselectivities but with a slight decrease on the final yield. Following the same synthetic strategy, two different prolinamides have been supported in a polystyrene resin, yielding catalysts $9 \mathbf{a}$ and $\mathbf{9 b}$ (Figure 2). Both catalysts $(10 \mathrm{~mol} \%)$ promoted the aldol reaction between acetone and cyclohexanone in a mixture of chloroform:water as solvent at $25^{\circ} \mathrm{C}$ in good results $(17-98 \%$ yield, $84-97 \%$ ee). Treatment of the resin with formic acid was neccessary in order to regenerate it, these catalyst species being reused up to sixteen and twenty two times, respectively, without detrimental of the observed results[63,64]. 

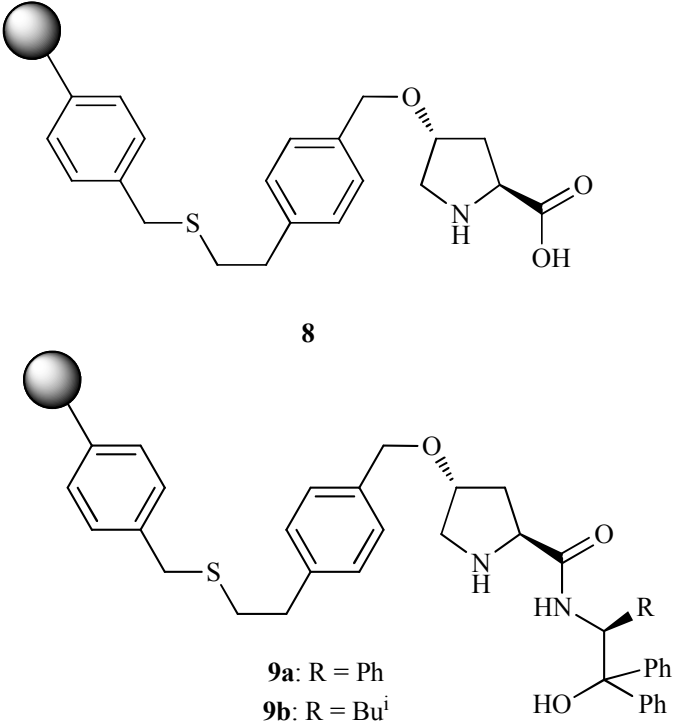

Figure 2. 4-Hydroxy-L-proline derivatives supported by means of thiol-ene reaction.

The cis-4-aminoproline moiety has been also anchored to polystyrene resins using standard chemical protocols. Hence, polymers 10, having a flexible spacer $(\mathrm{n}=2$ or 4$)$ or a rigid spacer 11 (5 mol\%, Figure 3), were tested in the aldol reaction between cyclohexanone and aromatic aldehydes to afford anti-4 products with similar yields and good diastereo- and enantioselectivities (46-94\%, 66-90\% de, $84-$ $96 \%$ ee) in a DMF/water (15:1) media. When the same reaction conditions were applied to the reaction of acetone or 2-butanone with aromatic aldehydes, lower yields and diastereoselectivies were achieved, albeit the enantioselectivities levels were maintained. The polymeric resins could be reused up to five times, a slightly decrease on the reactivity being observed $[65,66]$.
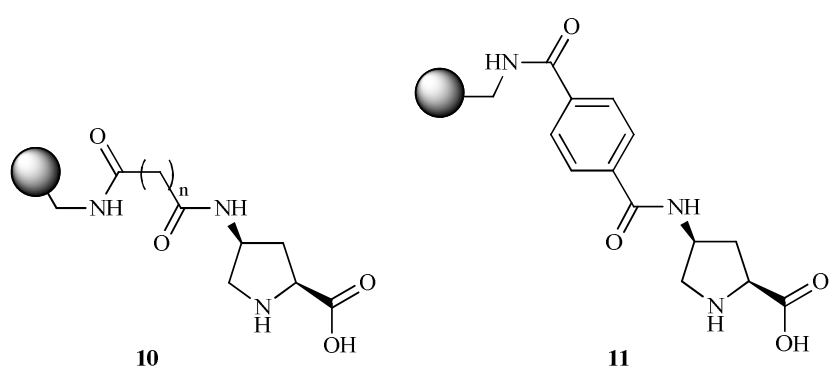

Figure 3. Immobilized cis-4-aminoproline derivatives.

In all the above described systems, the catalytic moiety was anchored to a commercially available or a conveniently functionalized synthetic polymer. This traditional 'postmodification' strategy has several limitations. Thus, it is impossible to modify the swelling properties of the polymer, and results quite expensive to be applied in large-scale synthesis. Another way to incorporate the catalyst in a polymeric matrix is applying a 'bottom-up' strategy. In this case, the polymeric catalyst is prepared by a copolymerization of the catalyst-functionalized monomer with other monomers and cross-linkers, following a modular approach. This protocol is more cost-efficient and therefore scalable, but also more synthetic challenging. In addition, just by changing the ratios or structures of the monomers, the chemical reactivity and physical properties, such as the solubility, can be fine-tuned. Moreover, the degree of incorporation of the active monomer to the polymeric matrix is easily controllable. Following this 'bottom-up' strategy, several methacrylates or acrylates derivatives were copolymerized with functionalized acrylic 4-hydroxyproline or prolinamide monomers by a free-radical reaction, giving acrylic polymer beads such as compounds $\mathbf{1 2}$ and $\mathbf{1 3}$, which were used as supported catalysts (5-10 mol\%, Figure 4) in water as solvent for the enantioselective synthesis of aldols 4 with similar results for all the different polymeric structures tested $(65-85 \%$ yield, $76-96 \%$ de, $97-98 \%$ ee). Different results were obtained when a soluble ketone such as acetone was used as pro-nucleophile with polymer 12 as catalyst, leading to poor results, whereas polymer 13 gave good yields and enantioselectivities (82-93\%, 90-91\% ee)[67]. These results allowed the use of catalyst $\mathbf{1 3}$ in a semi-continuously operating process in a packed-bed reactor, affording similar results to those achieved under batch conditions for at least five reaction cycles [68].
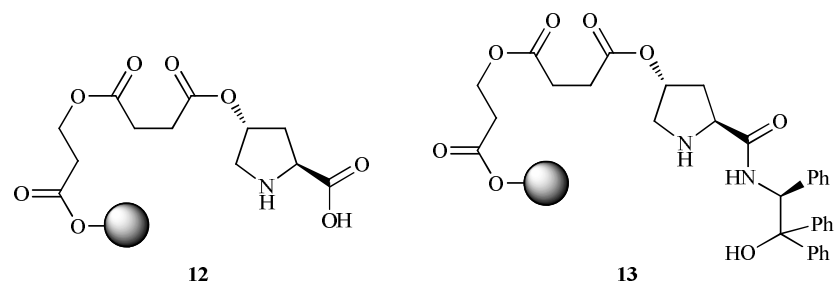

Figure 4. 'Bottom-up' strategy used for acrylic 4hydroxyproline or prolinamide immobilization.

L-Proline derivatives have also been anchored to different supports through the formation of an amide bond with the resin. The amide linkage is quite robust and stable and therefore the corresponding polymeric systems are easy to recover and reuse. For instance, prolinamides derived from 1,1'-binaphthyl-2,2'-diamine (Binam) are very efficient catalysts in the aldol reaction between cyclic, acyclic, alkyl and $\alpha$-functionalized ketones and aldehydes under different reaction conditions, including aqueous solvents [69-78]. Particularly the $N$-tosyl- $\left(R_{\mathrm{a}}\right)$-binam-D-prolinamide derivative has been shown as a very efficient organocatalyst for the intra- and intermolecular aldol reactions in aqueous and solvent-free media. However, this catalyst can only be recovered by direct column chromatography from the reaction media. Therefore, a vinyl derivative of similar structure was synthesized and grafted into a polystyrene resin to give a supported prolinamide system 14 (Figure 5). This polymeric organocatalyst $(\mathbf{1 4}, 20 \mathrm{~mol} \%)$ was used in the intermolecular aldol reaction in the presence of benzoic acid (5 mol\%) under dry and wet (55 equiv of water added) solvent-free conditions. Aldol products 4 were achieved usually in high yields, regio-, diastereo-, and enantioselectivities (22-83\% yield, 26-90 de, 73-88\% ee), these results being similar to those obtained under 
homogeneous conditions. However, the use of polymer 14 as catalyst gave moderate results (54\% yield, 62 de, $84 \%$ ee) in the cross aldol reaction between propanal and $p$ nitrobenzaldehyde. This supported catalyst was recovered by filtration and reused up to six times affording similar results [79]. The 'bottom-up' immobilization strategy was used for the synthesis of polymers containing the same $N$-tosyl- $\left(R_{\mathrm{a}}\right)$ binam-D-prolinamide moiety with different degree of crosslinking. Thus, polymer 15 (10 mol\%, Figure 5), containing $1 \%$ of divinylbenzene as cross-linker, was deployed in the aldol reaction between several ketones, including functionalized ones, and aromatic aldehydes under different reaction media, including solvent-free conditions. The best results $(25-88 \%$ yield, $10-76 \mathrm{de}, 53-93 \%$ ee) were achieved in the presence of a small amount of water (20 equiv) and benzoic acid $(2.5 \mathrm{~mol} \%)$. The catalyst was recovered after filtration and reused up to seven times without altering the achieved results [80].
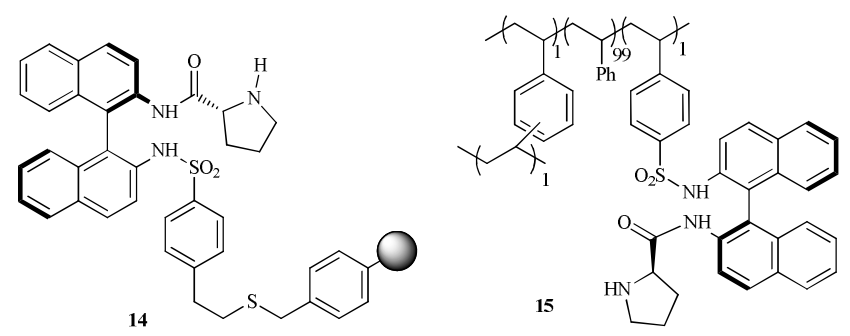

Figure 5. Polymer supported 1,1'-binaphthyl-2,2'-diamine prolinamides

Commercially available sulfonylpolystyrene was used as a support for different $1, n$-diamines, in order to study the influence of the length of the tether chain connecting the sulfonyl group of the polymer and the carboxamide group, the substitution on the nitrogen atom at the sulfonamide, and the presence of an additional stereocenter at the amine component on the stereoselection of the reaction. In the reaction between several cyclic ketones and aromatic aldehydes, the best results were obtained using the simplest ethylene diamine-polymer catalyst 16 (5 mol\%, Scheme 2) in the presence of $\mathrm{AcOH}$ as cocatalyst and in water as solvent $(40-95 \%, 36-90 \%$ de, $74-96 \%$ ee)[81]. This supported catalyst has also been employed in the intramolecular aldol reaction, a very important process, both in academia and industry, because it provides access to a chiral cyclic ketones found in a lot of natural and synthetic products with very interesting properties. Hence, the cyclization of compound $\mathbf{1 7}(\mathrm{n}=2$, Scheme 2$)$ allows the synthesis of the Wieland-Miescher ketone and analogues with applications in the pharmaceutical industry [82]. Polymer $16(\mathrm{n}=1,10 \mathrm{~mol} \%)$ in the presence of AcOH (10 mol\%) in water at $20{ }^{\circ} \mathrm{C}$ was able to catalyze this transformation with moderate results $(75 \%, 66 \%$ ee), although better results were achieved under solvent-free conditions [83].

Other resins and supports have been used to immobilize prolinamide derivatives. Thus, polyvinyl chloride-supported prolinamide-thiourea catalyst 19 (8 $\mathrm{mol} \%$, Figure 6) promoted the reaction between cyclohexanone and arylaldehydes in water as solvent with moderate results (17$81 \%, 0-50 \%$ de, $15-95 \%$ ee). This catalyst was recovered and reused for at least three times affording similar results [84].

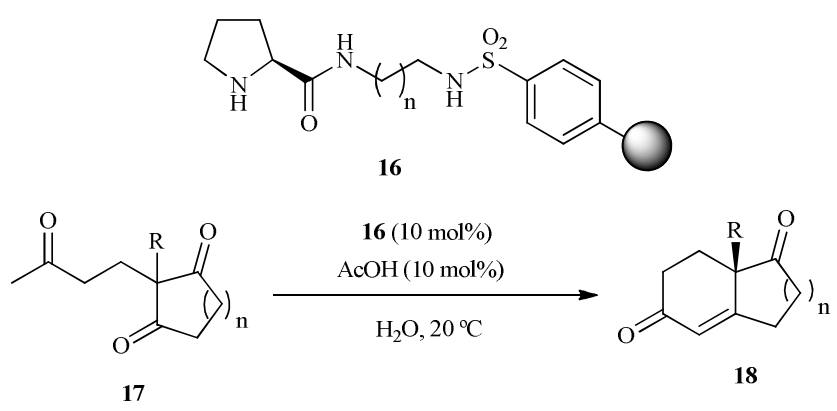

Scheme 2. Sulfonylpolystyrene supported prolinamide using different $1, n$-diamines linkers.

Although it was thought that the thiourea group of catalyst 19 would act as a weak Brønsted acid, thus stabilizing the transition state by formation of hydrogen bonds, the better results achieved $(18-99 \%, 14-84 \%$ de, $48-$ $92 \%$ ee) using polymeric catalyst 20 (5 mol\%, Figure 6) in the same reaction, and in the presence of a small amount of water showed that this assumption was wrong. Catalyst 20 resulted also active in the reaction between acetone and aromatic aldehydes albeit moderate results were achieved for the corresponding aldols $4(87-91 \%, 63-77 \%$ ee). This polymeric system was applied in a five-fold reaction cycle affording constant results [85]. Prolinamide has also been supported on natural chitosan, leading to catalyst 21 (15 mol\%, Figure 6) which was applied in the reaction between cyclohexanone and acetone with arylaldehydes in water in the presence of Tween-20 as a surfactant. The use of the surfactant improved the results $(42-95 \%, 50-88 \%$ de, $41-$ $92 \%$ ee) due to the formation of an aqueous micelle that acted as a hydrophobic pocket, allowing the solution of the reactants. However the system was not recovered or reused after the reaction [86].
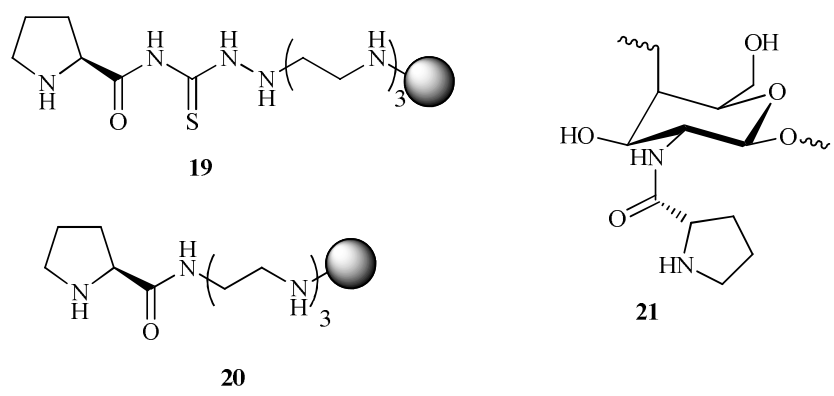

Figure 6. Other resins and supports used to immobilized proline derivatives.

Not only proline and its derivatives have been supported on organic polymeric resins, but also other catalytic moieties have been grafted into them and used under aqueous conditions. For instance, a series of primary amino acids were covalently bonded onto polystyrene through a 1,3- 
dipolar cycloaddition, and were used in the aldol reaction between cyclohexanone and $p$-nitrobenzaldehyde, the threonine supported system 22 (10 mol\%, Figure 7) showing the best catalytic performance in DMF: $\mathrm{H}_{2} \mathrm{O}(92: 8)$. These conditions were applied in the reaction between aromatic aldehydes with a variety of cyclic ketones, acetone, $\alpha$ hydroxyketone and protected dihydroxyacetone (70-96\%, $16-76 \%$ de, $46-95 \%$ ee), the catalyst being recovered and reused at least five times affording similar results [87]. In addition, a tripeptide supported in a polyethyleneglycol grafted on cross linked polystyrene $(\mathbf{2 3}, 20 \mathrm{~mol} \%$, Figure 7) in the presence of $\mathrm{ZnCl}_{2}(20 \mathrm{~mol} \%)$ was applied as catalytic combination in the reaction between acetone and arylaldehydes. Good yields and acceptable enantioselectivities (89-100\%, 71-74\% ee) were achieved working in a mixture of acetone: $\mathrm{H}_{2} \mathrm{O}$ :THF $(1: 1: 1)$ as solvent. This catalyst was reused in a four-fold reaction without detrimental on the results [88]. Moreover, cinchonine has also been supported into a polymeric support following the 'bottom-up' strategy. Thus, several systems $\mathbf{2 4}$ with different chemical compositions of acrylonitrile and a cinchonine derivative (7.5 mol\%, Figure 7) have been evaluated as supported catalysts in the aldol reaction. The best results were achieved using a polymer with a low content in cinchonine $(1 / 25 \mathrm{x} / \mathrm{y}$, monomer ratio). This catalyst, in combination with triflic acid $(10 \mathrm{~mol} \%)$, was used in the reaction between cyclic ketones and aromatic aldehydes in water as solvent $(18-98 \%, 22-98 \%$ de, $61-98 \%$ ee), its recovery and reuse being possible for seven cycles, with only a small drop in conversion after the fifth cycle [89].<smiles>C[C@H](OCc1cn(Cc2ccccc2)nn1)[C@@H](N)C(=O)O</smiles>

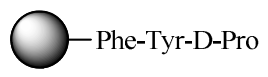
22 23

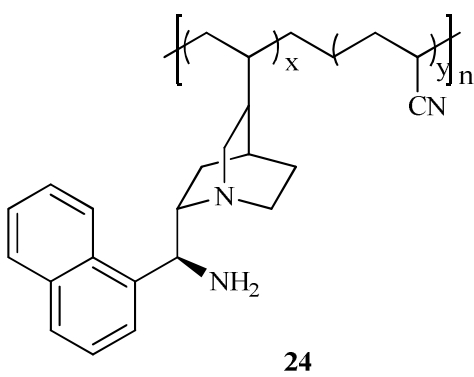

Figure 7. Other organocatalysts grafted into organic polymeric resins.

Inorganic supports have also been used to immobilize organocatalysts, the most frequently used being silica containing organic appendages [90]. These organosilicasupported organocatalysts combine the advantages of a silica matrix (high surface area, mechanical and thermal stability and chemical inertness) with the properties of the organocatalyst. Interesting classes of organosilicas are the bridged silsesquioxanes, obtained by a sol-gel methodology form bridged organosilanes, which have low porosity but high homogeneity and loading of organic fragments. Following this methodology, an aminoindanone derived prolinamide was incorporated to a silica matrix leading to compound 25a (Figure 8) that was tested as catalyst (16 $\mathrm{mol} \%$ ) in the intra and intermolecular aldol reaction in water as reaction media, affording moderate results of products anti-4 (96-99\%, 26-94\% de, 50-74\% ee) and $18(\mathrm{n}=2,74 \%$, $43 \%$ ee). The catalyst was reused for five times achieving similar results [91]. From the related monosilylated product, several hybrid materials of type $\mathbf{2 5 b}$ (Figure 8) were prepared by sol-gel condensation with different amounts of tetraethyl orthosilicate (TEOS) and by grafting on a mesostructured silica. The catalytic activity of these systems (10 mol\%) were evaluated in the aldol reaction between cyclohexanone and $p$-nitrobenzaldehyde (97-99\%, 62-72\% de, $82-88 \%$ ee) in water as solvent, showing that the porosity of the material does not affect yields nor selectivities, while the less porous material $(n=5)$ shows a lower reaction rate. These catalysts were also applied in the intramolecular aldol reaction to afford product $\mathbf{1 8}$ albeit with moderate results $(60-82 \%, 42-48 \%$ ee). While reusing the catalysts in the intermolecular process was possible for five reaction cycles, in the intramolecular reaction the results were only reproducible for three reaction cycles [92].

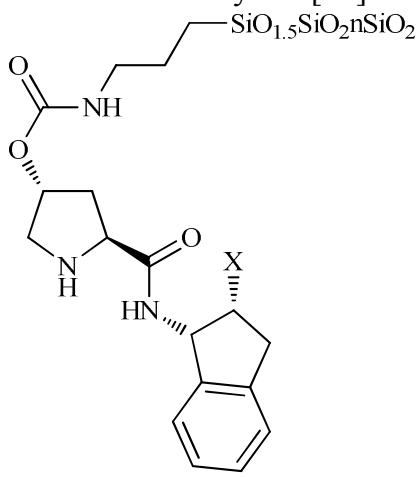

$$
\begin{aligned}
& \text { 25a: } \mathrm{X}=\mathrm{CO}_{2} \mathrm{NH}\left(\mathrm{CH}_{2}\right)_{3} \mathrm{SiO}_{1.5} \\
& \text { 25b: } \mathrm{X}=\mathrm{H}
\end{aligned}
$$

Figure 8. Aminoindanone derived prolinamide immobilized into a silica matrix.

The trans-4-hydroxyproline motif has also been incorporated through a carbamate-type linker to the structured mesoporous material MMCM-41 (26, Scheme 3) and screened as catalyst in the aldol reaction between 2,2dimethyl-1,3-dioxane (28) and a chiral aldehyde derived from tartaric acid, leading to product 29. After hydrogenation, this compound gave azasugars, which are important inhibitors of enzymes involved in carbohydrate processing. The best performance of this catalyst was achieved in toluene as solvent in the presence of only 5 equiv of water [93]. 


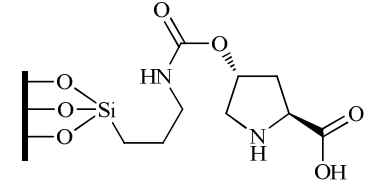<smiles>N[C@@H]1COC(c2ccccc2)OC1C=O</smiles>

27

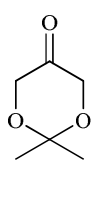

28
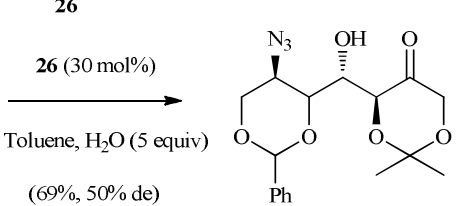

anti-29
Scheme 3. Aldol reaction between 2,2-dimethyl-1,3-dioxane and a chiral aldehyde.

Recoverable silica-gel supported organocatalyst 30 (10 mol\%), combined to benzoic acid $(5 \mathrm{~mol} \%)$ and in the presence of a small amount of water (12 equiv) was very efficient as catalyst in the intermolecular aldol reaction, affording products $\mathbf{4}$ in high yields, regio-, diastereo- and enantioselectivities (48-95\% yield, 36-100\% regioselectivity, $42-90 \%$ de, $50-95 \%$ ee). Under these reaction conditions, the cross-aldol reaction between propanal and $p$ nitrobenzaldehyde gave also good results $(75 \%$ yield, $76 \%$ de, $97 \%$ ee). The recovered catalyst was reused up to nine times providing similar results. Remarkably, this heterogeneous organocatalyst $\mathbf{3 0}$ allowed the synthesis of the Wieland-Miescher ketone and analogues $\mathbf{1 8}$ in good results (73-91\% yield, $80-91 \%$ ee), its reuse up to five times being possible without observing changes in the results [94]. Moreover, this silica-supported bisprolinamide was active in the synthesis of Tacrine precursors of type 33 (Scheme 4), which are potent acetylcholinesterarease inhibitors and have been applied as drugs in neurodegenerative disorders. The catalysts was recovered and reused for at least five times without any changes on the results [95].
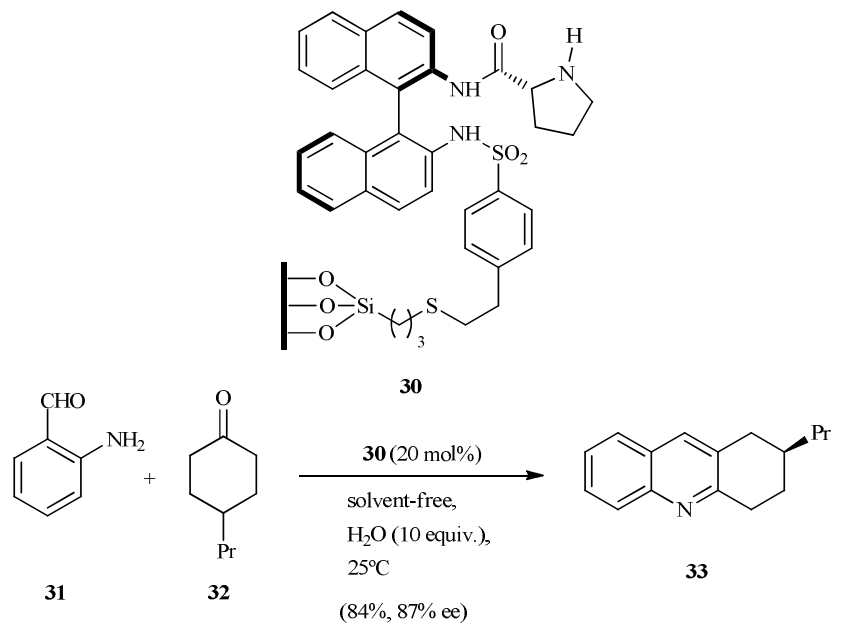

Scheme 4. Synthesis of Tacrine precursors using silica-gel supported organocatalyst $\mathbf{3 0}$.

Another inorganic support for organocatalysts are magnetic nanoparticles (MNP) which form a colloidal suspension, thus offering quasi homogeneous conditions.
Once the reaction has been completed, the magnetic organocatalysts can be easily separated from the reaction mixture by decantation of the supernatant after retaining the nanoparticles using an external magnet. These superparamagnetic materials are robust and have large surface area, high dispersion, stability as well as low price and toxicity [96]. There are only a few examples, all of them employing nanomagnetite $\left(\mathrm{Fe}_{3} \mathrm{O}_{4}\right)$ as support, were MNPsupported organocatalysts have been used in enantioselective reactions. For instance, chiral 1,2-cyclohexyldiamine has been immobilized on magnetic nanoparticles, leading to system 34 (20 mol\%, Figure 9) which has shown a good performance in the aldol reaction between acetone or cyclohexanone with aromatic aldehydes (53-98\% yield, 33$84 \%$ de, $84-98 \%$ ee), working in the presence of trifluoracetic acid, in water at $25{ }^{\circ} \mathrm{C}$ as solvent. This catalytic system was magnetically recovered from the reaction media and reused up to seven cycles with unchanged activity. The nanospheric dimensions as well as the silica coating were maintained after these reaction cycles, a slight aggregation being observed [97]. Instead of the former silica-coating of the MNP silanization procedure to link the MNP with the catalyst, a phosphonic acid was directly used as anchor point to fix several cinchonidine derivatives to magnetite MNP through a co-precipitation method, affording systems 35 (5 mol\%, Figure 9). The optimal results in the aldol reaction between cyclohexanone and several aromatic aldehydes using water as solvent were achieved using the catalyst bearing an arm chain of length $\mathrm{n}=4$ and catalyst loading $0.52 \mathrm{mmol} / \mathrm{g}(36-100 \%, 64-96 \%$ de, $75-9 \%$ ee). Using a simple magnet, this system was recovered and reused six times achieving almost identical results [98].
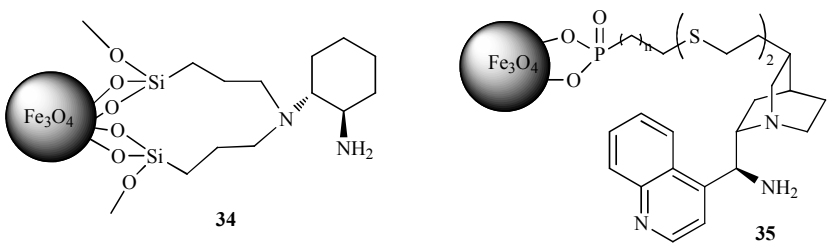

Figure 9. Magnetic supported organocatalysts.

The same cinchonidine derivative was attached to porous zirconium through the same phosphonate linkage, giving compound 36 (Figure 10). These zirconium-phosphonate materials are insoluble in water and organic solvents and have a layered or pillared structure. Again, the system with an arm chain of length $\mathrm{n}=4(10 \mathrm{~mol} \%)$ led to the best results in the aldol reaction between cyclohexanone and arylaldehydes in the presence of triflic acid in water as solvent $(12-98 \%, 36-96 \%$ de, $5-99 \%$ ee). This catalyst was recovered by centrifugation and reused, after treatment with a $\mathrm{Et}_{3} \mathrm{~N}$ solution (30 wt\%), for at least five cycles [99]. This layered inorganic backbone may be considered as a hook onto which organic groups with different functionalities may be attached, which allows controlling both the reactivity and selectivity of the organic catalyst. Thus, 4-trans-hydroxy-Lproline was also attached to a zirconium layered material 
through methyl and/or phenyl phosphonate or phosphate groups affording systems 37 . These systems were tested as supported catalyst for the aldol reaction between cyclohexanone and $p$-nitrobenzaldehyde in DMF/water as solvent, giving mainly anti-4, the best results being achieved when both methyl and phenyl phosphonates were present in the structure $(51 \%, 78 \%$ de, $93 \%$ ee). The catalysts were recovered by centrifugation and reused. However their acid sensitivity and hydrolysis tendency led to unsatisfactory results [100].
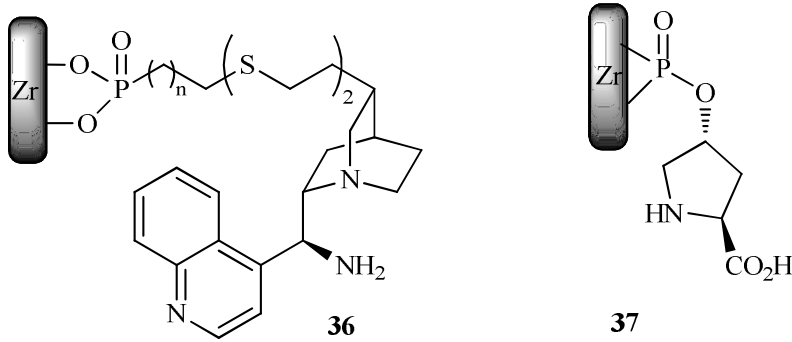

37

Figure 10. Zirconium supported orgaonocatalysts.

The use of hybrid inorganic-supported organocatalyst led to systems suitable to work under heterogeneous conditions. However, the immobilization of organocatalyst to ionic liquid systems gave catalyst which can be used either under organic or aqueous homogeneous conditions [101]. Hence, several functionalized ionic liquids have been attached to the pyrrolidine motif after quaternization of the pyrrolidineimidazole precursor. These systems were evaluated in the reaction between cyclohexanone or cyclopentanone with aromatic aldehydes in the presence of water $(100 \mathrm{~mol} \%)$ and acetic acid (5 mol\%), catalyst 38 (20 mol\%, Figure 11) giving the best results $(66-92 \%, 0-66 \%$ de, $5-63 \%$ ee). The catalyst was recovered and reused six-fold obtaining a similar enantiomeric excess but lower yields and diastereoselectivities [102]. Better results were observed using ionic liquid-functionalized 4-trans-hydroxy-L-proline derivatives 39 (Figure 11), although a higher catalyst loading (30 mol\%) was necessary to afford the corresponding aldol products $(20-95 \%, 71-94 \%$ de, $80-99 \%$ ee) in water as solvent. The catalyst was recovered from the reaction by extraction and reused up to five times without detrimental on the achieved results [103]. A higher recyclability, up to 8 cycles, was displayed using compound 40 (15 mol\%, Figure 11 ) as catalyst in the aldol reaction between an array of cyclic ketones and aromatic aldehydes in water at $25{ }^{\circ} \mathrm{C}$, giving good yields (38-97\%) and excellent diastereo- and enantioselectivities $(60-94 \%$ de, $92-99 \%$ ee) [104]. The use of the more lipophilic counteranion $\mathrm{Tf}_{2} \mathrm{~N}^{-}$, led to the system 41a (5 mol\%, Figure 11) which showed extremely efficient in the reaction between cyclohexanone and aromatic aldehydes in water at $25{ }^{\circ} \mathrm{C}$ (41-98\% yield, $82-96 \%$ de, $96-$ $99 \%$ ee). The catalyst loading could be decreased to 0.1 mol\% when high electrophilic aromatic aldehydes were used, without compromising the enantioselectivity of the process. However, lower yields were achieved using aliphatic aldehydes as electrophiles (52-60\%), but still excellent diastereo- and enantioselectivities (99\% de, 99\% ee). Under these conditions, the catalyst was recovered and reused up to five times without deleterious effect in the results $[105,106]$.

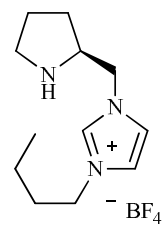

38<smiles>C[n+]1ccc(C(Br)CBr)cc1</smiles>

40

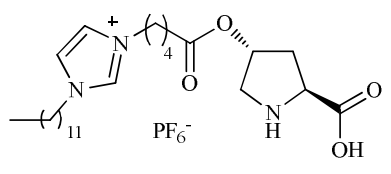

39

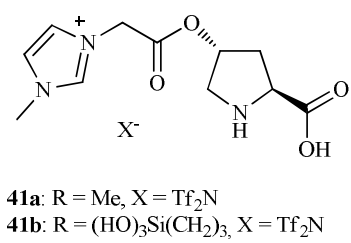

Figure 11. Immobilization of organocatalyst into ionic liquid systems.

System 41b (10 mol\%, Figure 11) was completely insoluble in ether and highly soluble in water due to the presence if a hydrophilic cation and a lipophilic anion. Its catalytic efficiency in the reaction between cyclohexanone and aromatic and aliphatic aldehydes was good (50-98\% yield, $90-99 \%$ de, $99 \%$ ee). Although this catalyst was designed to improve its recyclability properties, the achieved yields were highly compromised after the third reaction cycle, although the stereoselectivity of the process was maintained up to five runs [107].

Prolinamides have also been modified by attaching a ionic liquid moiety. For instance, ionic liquid-tagged 4hydroxyprolinamide derived from $(S)$-diphenylvalinol 42 (2$5 \mathrm{~mol} \%$, Figure 12) has been used in the aldol reaction between cyclic ketones and alkyl and aryl aldehydes in water at $25{ }^{\circ} \mathrm{C}$ or $3{ }^{\circ} \mathrm{C}$, respectively. Both aromatic and aliphatic electrophiles provided the aldol products with good results $(38-99 \%, 24-98 \%$ de, $75-99 \%$ ee). Once recovered by extraction, the catalyst could be reused for three cycles affording similar results, albeit a drop in conversion was observed in the fourth run [108]. The use of two ionic tags showed more efficient, providing a catalyst with a higher recyclability. Thus, $C_{2}$-symmetric prolinamide 43 (10 mol\%) was employed as catalyst in the reaction between cyclic ketones with aromatic and heteroaromatic aldehydes, in the presence of water (100 equiv.) as solvent, affording products 4 in good results $(40-99 \%, 22-98 \%$ de, $25-99 \%$ ee). The use of acyclic ketones as pro-nucleophiles led to lower conversions and enantioselectivities (15-99\%, 39-68\% ee). As expected, this catalytic system was recovered and reused at least 10 reaction cycles giving similar results [109]. In addition, instead of using a chiral 1,2-cyclohexanodiamine as a bridge between the two prolinamide units, other systems derived from more simple diamines such as 1,2diaminobenzene, 1,4-diaminobenzene and 1,2diaminoethane were evaluated in the aldol reaction under 
similar reaction conditions, leading to similar results. Remarkably, catalyst derived from 1,4-diaminobenzene showed very robust, being recycled up to fourteen times without detrimental on the results [109].
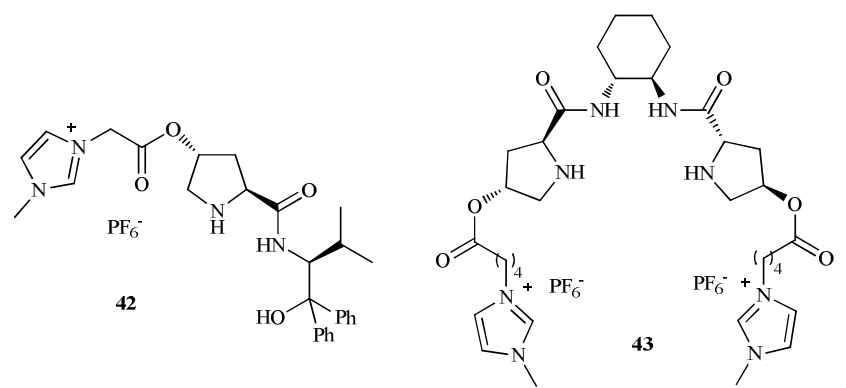

Figure 12. Ionic liquid-tagged supported prolinamides.

As shown above, one of the limitations of the use of the ionic-tag strategy is the recyclability of the obtained catalysts. Thus, most of the reported systems are partially soluble in water or organic solvents and, therefore, are lost during the extractive work-up needed for the recovery. To overcome this disadvantage, an ionic liquid-functionalized organocatalyst $\mathbf{4 4}$ has been grafted onto MNP coated with silica and it has been used as catalyst (10 mol\%, Figure 13) in water at $30^{\circ} \mathrm{C}$ as solvent, affording better results (30-96\%, $34-98 \%$ de, $45-89 \%$ ee) than when using the related ionic liquid-free supported system. Catalyst $\mathbf{4 4}$ was recovered for the reaction mixture by using a simple magnet and reused five times leading to similar results. Moreover, the inactivity of the supernatants and the maintenance of the nitrogen percentage of the recovered catalyst demonstrated that no leaching of the active species occurs into the solution, and confirmed the stability and robustness of the system [110].

Another way to increase the recyclability without losing the advantages of the use of homogeneous conditions is to entrap the ion-tag catalyst into the liquid film of a multilayered ionic liquid covalently bonded to silica gel, like in system 45 (Figure 13). Thus, system 45 (5 mol\%) was used as catalyst in the aldol reaction between cyclohexanone and aromatic aldehydes in the presence of water, affording products 4 in excellent yields, diastereo- and enantioselectivities (81-99\%, 78-94\% de, $87-98 \%$ ee). Really short reaction times (usually $2.5 \mathrm{~h}$ ) were observed for these reactions, which were performed just changing the aldehyde counterpart and using the same catalytic batch that was recycled and reused for fifteen times. Remarkably, no traces of cross contamination were observed in any of the products. This reaction took place under a two stage liquid-liquid biphasic homogeneous conditions, with the immobilized ionic liquid acting as a catalyst reservoir, delivering the active catalyst to the cyclohexanone phase and capturing the catalysts once the organic phase (products and reactants) were removed [111]. In addition, a very simple organocatalytic approach was developed by using a polyvinylidene chloride supported ionic liquid (18 $\mathrm{mol} \%$ ) combined to simple proline $(12 \mathrm{~mol} \%)$ as catalytic system for the aldol reaction of cyclohexanone, acetone, and 2- butanone and arylaldehydes in water at room temperature (74-99\%, 4-88\% de, 67-98\% ee). The catalytic system was recovered by extraction of the aldol products, and reused at least six times achieving comparable results [113].
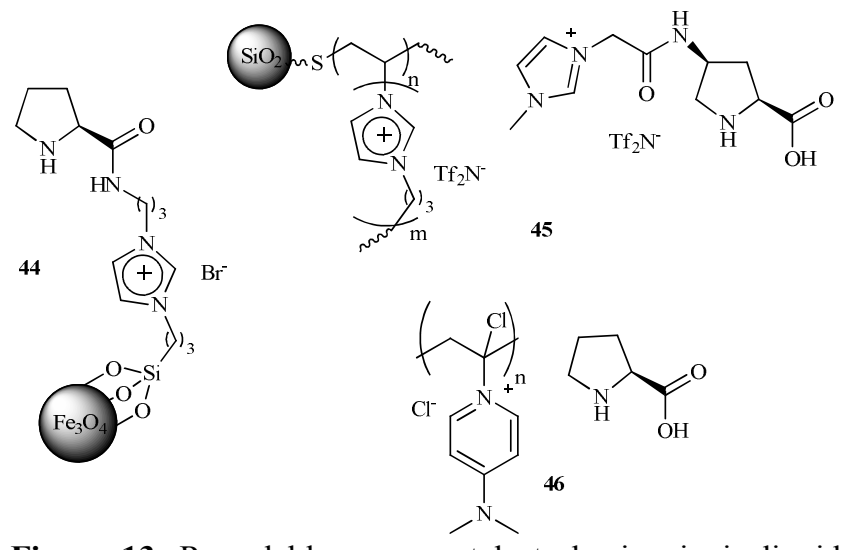

Figure 13. Recyclable organocatalysts having ionic liquid moieties.

The attachment of organocatalysts to dendrons was other strategy to afford systems that acted as homogeneous catalysts, being suitable to recycling due to their high molar mass [114-116]. Thus, functionalization of proline sulfonimide with Fréchet dendritic wedges provided dendrimers 47a-c (10 mol\%, Figure 14), which were evaluated as catalysts in the reaction between cyclohexanone (2 equiv.) and $p$-nitrobenzaldehyde in pure water as solvent at $25{ }^{\circ} \mathrm{C}$, yielding mainly the isomer anti-4 with excellent results (86-92\% yield, $94-98 \%$ de and $98-99 \%$ ee). The best results were achieved using catalyst $47 \mathbf{b}(n=1)$ due to the hydrophobic effect of the dendritic wedges. This catalyst was recovered by precipitation using a $n$-hexane:ethyl acetate mixture and reused five-fold obtaining similar results [117].

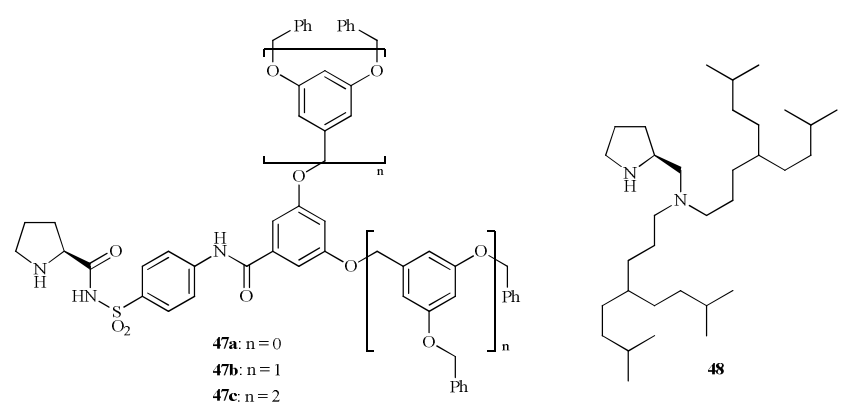

Figure 14. Organocatalysts attached to dendrons.

System 48 having a proline-derived core and nonpolar hydrocarbon dendrons behaved as an amphiphilic species The use of this catalyst $(10 \mathrm{~mol} \%$, Figure 14) in the aldol reaction between cyclohexanone and aromatic aldehydes, in the presence of trifluoroacetic acid in water at $23{ }^{\circ} \mathrm{C}$, gave good results (5-95\% yield, $28-66 \%$ de, $35-93 \%$ ee) [118]. 


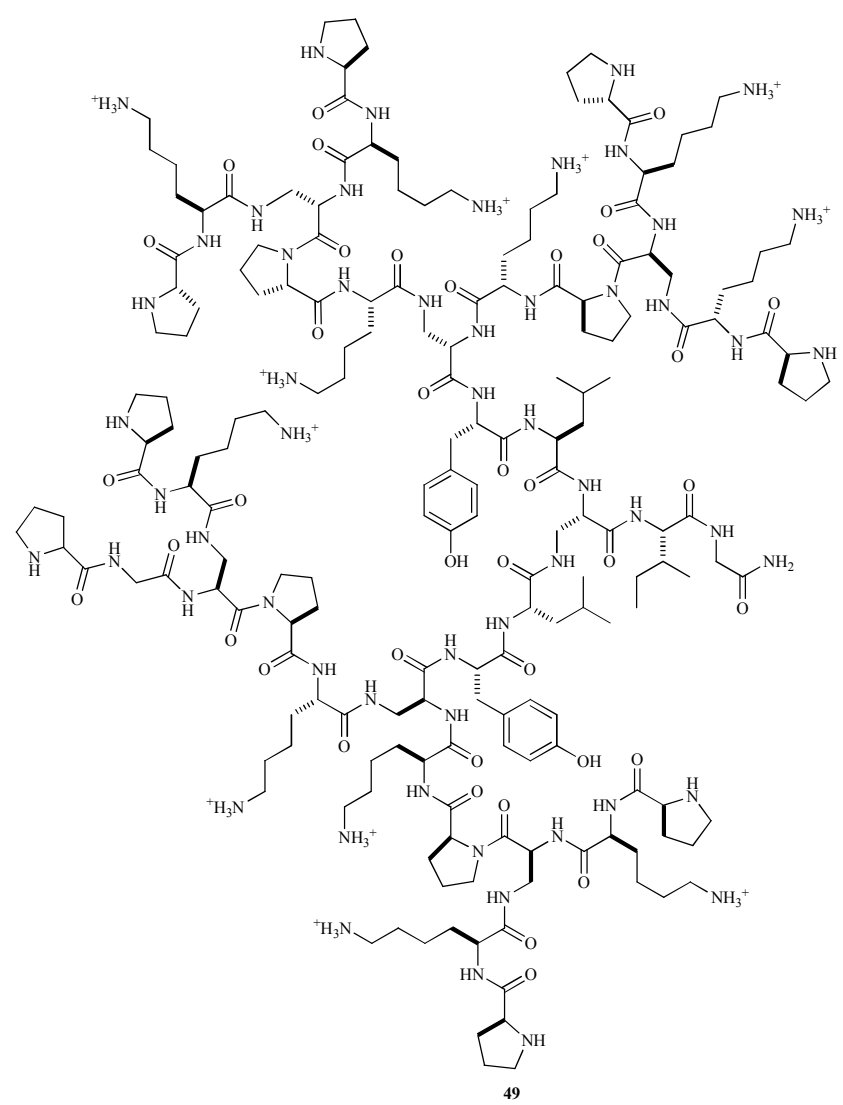

Figure 15. Proline-derived core with nonpolar hydrocarbon dendrons organocatalyst.

Peptidic dendrimers of type $\mathbf{4 9}$ having lysine and proline residues at the core and near the surface, presented a structure that resembled the aldolase enzymes. They were synthesized by a combinatorial approach using the split-and mix methodology. The peptide dendrimers of the libraries contained eight variable amino acids positions along three successive branches. Using four different amino acids per variable position resulted in a combinatorial library of 65,536 members. The library containing free $N$-termini, $N$ terminal proline or lysine at the surface, showed to be active in the aldol reaction between cyclohexanone and $p$ nitrobenzaldehyde in an aqueous buffer solution $(\mathrm{pH} 8.5)$, affording the corresponding aldol in 54\% yield, $33 \%$ de and $65 \%$ ee. Unfortunately, although these dendritic peptides are active in the reaction between acetone and dihydroxyacetone under aqueous conditions, the aldol products were obtained as racemic mixtures [119].

\subsection{Aqueous Michael reactions with supported organocatalysts}

The Michael addition is a basic $\mathrm{C}-\mathrm{C}$ bond forming reaction that allows the synthesis of 1,5-difunctionalized compounds. In the last years a considerable effort has been made to design efficient organocatalysts to perform this reaction in an asymmetric way [120-122] and even under aqueous conditions [123]. Generally, two approaches have been used to accomplish this transformation using chiral organocatalysts. In the first one, a chiral bifunctional organocatalyst activates simultaneously the ketone carbonyl function and the $\alpha, \beta$-unsaturated compound, while in the second a substituted chiral amine (frequently pyrrolydine derivatives) creates an enamine intermediate in which the attack of the electrophile occurs through its less hindered diastereotopic face.

One of the most explored Michael type reactions using organocatalyst is the 1,4-addittion of carbonyl compounds to nitroalkenes 50, which affords versatile functionalized products $\mathbf{5 2}$, mainly as $s y n$-isomers.

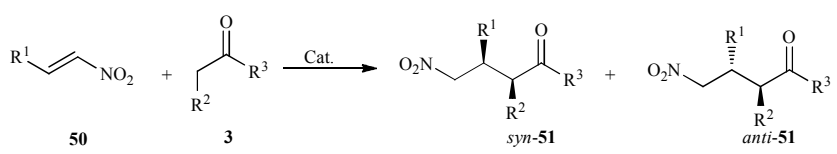

Scheme 5. Organocatalyzed 1,4-addittion of carbonyl compounds to nitroalkenes.

For this type of transformation, the immobilization of the organocatalysts has been achieved using a covalent attachment to polystyrene resins such as in catalysts $\mathbf{5 2 - 5 4}$ (Figure 16). Catalyst $52(10 \mathrm{~mol} \%)$ has been used as promoter, its best results being achieved in dichloromethane as solvent. However, a high yield, as well as diastero- and enantioselectivity $(97 \%, 92 \%$ de, $99 \%$ ee) was also accomplished in the reaction between propanal $\left(3 \mathbf{a}, \mathrm{R}^{2}=\mathrm{Me}\right.$, $\left.\mathrm{R}^{3}=\mathrm{H}\right)$ and $\beta$-nitrostyrene in the presence of dimethylpoly(ethylene glycol) (diMePEG, $10 \mathrm{~mol} \%$ ) in water as solvent [124]. In addition, a broad substrate scope was shown by using polystyrene-immobilized catalyst $\mathbf{5 3}$ (10 $\mathrm{mol} \%$ ) in the presence of $p$-nitrobenzoic acid, in water at room temperature. Thus, very high selectivities were achieved in the conjugate addition of cyclic and acyclic ketones or aldehydes with nitrostyrenes and $\beta$-alkyl substituted nitroolefins (42-100\%, 76-94\% de, $74-93 \%$ ee). This catalyst was recovered by filtration and reused in six consecutive runs without significant loss of activity or enantioselectivity [125]. Moreover, the Merrifield-supported pyrrolydine system $54(10 \mathrm{~mol} \%)$ resulted very active as catalyst in the addition of cyclic and acyclic ketones to nitrostyrenes in the presence of DiMePEG (10 mol\%) in water as solvent, the best results $(40-85 \%, 78-98 \%$ de, $26-$ $99 \%$ ee) being achieved when a $p$-phenylene group was present in the resin as a linker. Linear aldehydes could also be used as substrates but only moderate enantioselectivities were found $(81-99 \%, 74-92 \%$ de, $48-62 \%$ ee). The catalytic performance of the resin resulted maintained after three reaction cycles [126]. 
52

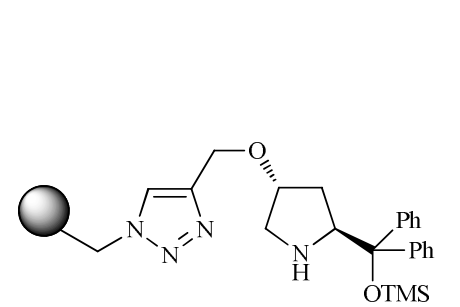

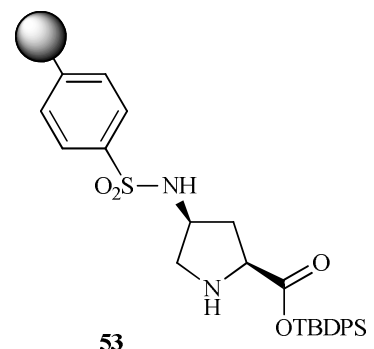

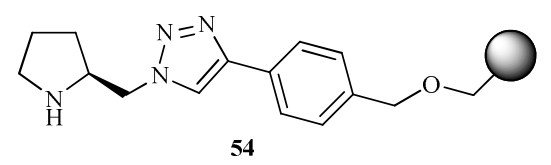

Figure 16. Immobilized organocatalysts attachment to polystyrene resins.

The use of ion-tagged catalysts allowed performing the reaction under homogeneous conditions. Thus, catalyst 55 (1 mol\%) showed very efficient in the Michael addition of propanal $\left(3 \mathbf{a}, \mathrm{R}^{2}=\mathrm{Me}, \mathrm{R}^{3}=\mathrm{H}\right)$ and $\beta$-nitrostyrene in water as solvent, affording product $s y n-51$ in $98 \%$ yield, $86 \%$ de and $99 \%$ ee. This catalytic system gave the best results in the reaction between propanal and aromatic nitroalkanes in dichloromethane as solvent, although water showed to be the ideal media when the less reactive aliphatic nitroalkenes or large aliphatic aldehydes were used as substrates. Water was also the best reaction media to perform the reaction between sterically hindered nitroalkenes and aldehydes, the addition of benzoic acid as cocatalyst being necessary to afford the highest enantioselectivities. Unfortunately, the recycling of the catalyst was not studied [127]. In addition, surfactanttype chiral catalyst $56(20 \mathrm{~mol} \%)$, without needing an acid additive, was used to promote the reaction of cyclohexanone $\left[3 \mathbf{b}, \mathrm{R}^{2}=\mathrm{R}^{3}=\left(\mathrm{CH}_{2}\right)_{4}\right]$ and $\beta$-nitrostyrene derivatives in water as solvent, giving the corresponding syn-52 products, which precipitate in the water solution, in good results (83$99 \%, 86-98 \%$ de, $91-98 \%$ ee). However, the use of acetone as pro-nucleophile was not successful [128].

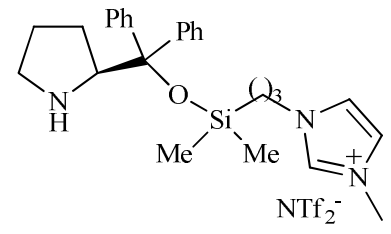

55

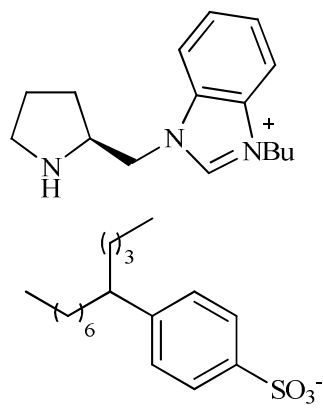

56
Figure 17. Ionic liquid derived organocatalysts used in the Michael addition.

Diarylprolinol silyl ether species of type 57 (3-10 mol\%) in the presence of benzoic acid (10-30 mol\%) catalyze efficiently the conjugate addition of aldehydes to nitroolefins, even using acetaldehyde as donor, in water or brine as solvent, leading to the corresponding products in excellent results $(30-97 \%, .90-96 \%$ de, $80-99 \%$ ee). The catalytic system was recovered by extraction of the products with the appropriate organic solvents, and reused six times giving similar results $[129,130]$. This catalytic system was successfully applied in the asymmetric domino [131,133] Michael/Henry reaction of pentane-1,5-dial (3c) with nitroolefins, giving the expected products $\mathbf{5 8}$ in high yields and enantioselectivities (Scheme 6), the catalyst being recycled up to four times [134].

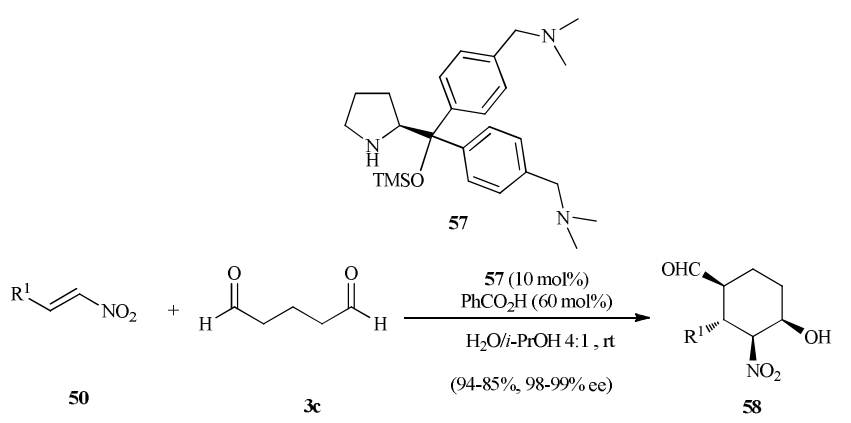

Scheme 6. Michael/Henry reaction catalyzed by recyclable diarylprolinol silyl ether derivative.

In the former reaction, the separation of the acid cocatalyst from the reaction products, since both were soluble in organic media, resulted extremely difficult. In order to avoid this problem, an ionic liquid-supported (ILS) benzoic acid 60 was used as cocatalyst. Hence, the catalytic combination 59a (3 mol\%) and ILS 60 (21 mol\%) was used in the reaction of aliphatic aldehydes with aryl and alkyl nitroolefins in water at $25^{\circ} \mathrm{C}$, giving good yields $(74-98 \%)$ and excellent diastereo- and enantioselectivities (88-98\% de, $99 \%$ ee). The catalytic system was recovered by extraction of the product form the reaction media, and reused twelve times, observing a drop in the yield after the ninth cycle but keeping the enantioselectivity [135]. Comparable results were obtained by using catalyst $59 \mathrm{~b}(5 \mathrm{~mol} \%)$ in the presence of 6 equiv of the ionic liquid $\mathbf{6 0}$ for the conjugate addition of pentanal $\left(\mathbf{3 d}, \mathrm{R}^{2}=n \mathrm{Pr}, \mathrm{R}^{3}=\mathrm{H}\right)$ with nitroolefins, this system being recycled and reused ten cycles. Again, no detrimental of the enantioselectivity was observed during the reaction cycles, although a noticeable decrease of the yield was observed after the sixth run [136]. Following the same strategy, different pyrrolidine-based organocatalysts of the type $\mathbf{6 1}$ have been synthesized and used, in the presence of an ionic liquid-supported acid, for the conjugate addition of cyclohexanone and other cyclic ketones to nitrostyrenes. The best results were achieved using a combination of catalyst $\mathbf{6 1}$ and sulfonic acid $\mathbf{6 2}(10 \mathrm{~mol} \%)$, leading to good selectivities $\left(42-96 \%\right.$ de, $57-96 \%$ ee) in water at $25{ }^{\circ} \mathrm{C}$. However, the recycling of this system was not attempted [137].

The introduction of a fluorous tag into the catalysts can facilitate its recovery by using fluorous silica gel-based solid-liquid extraction. For this purpose, catalyst 63 was designed and used (10 mol\%) in the reaction between cyclic ketones and aliphatic aldehydes with nitrostyrene derivatives 
in water at solvent. The Michael products syn-51 were obtained in good results $(60-98 \%, 50-96 \%$ de, $68-95 \%$ ee), the catalyst being recycled by solid-liquid extraction and reused for six times. Although the enantioselectivities were retained over the cycles, the yields and diastereoselectivities dropped after the second cycle. However, when the same catalyst was used in the aldol reaction between ketones and aromatic aldehydes to give products anti-4 (Scheme 1, 75$93 \%, 0-90 \%$ de, $70-97 \%$ ee), only slight decreases on the activity and selectivity were observed after seven reaction cycles $[138,139]$.

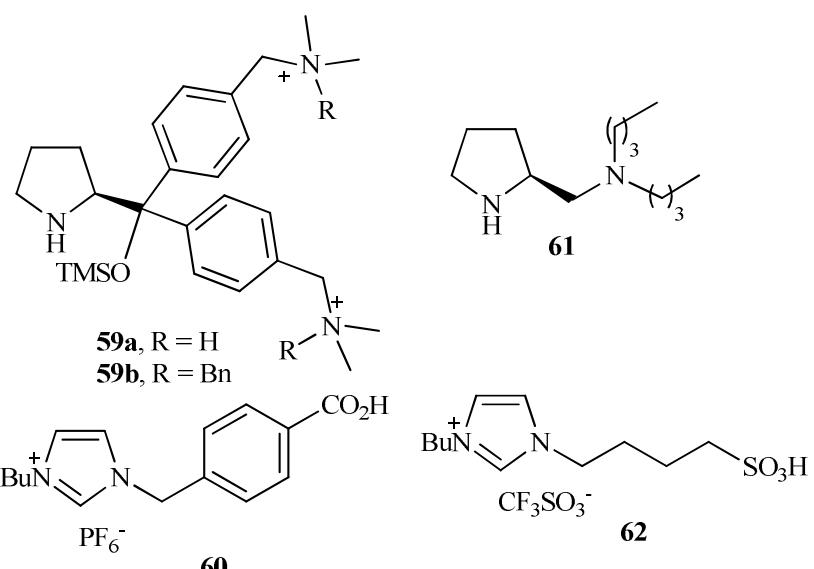

60<smiles>FC(F)(F)C(F)(F)[SiH2]NC[C@@H]1CCCN1</smiles>

Figure 18. Other recyclable organocatalysts used in the Michael addition to nitroolefins.

Besides the use of nitroolefins as electrophiles in the Michael addition, other $\alpha, \beta$-unsaturated compounds have been employed in this type of transformation. For instance, diarylprolinol silyl ether 57, combined to the ILS sulfonic acid 62, has been used in the Michael reaction of maleimides 64 with aldehydes, leading to the chiral succinimide derivatives $\mathbf{6 5}$ in moderate yields and diastereoselectivities, but with high enantioselectivities (Scheme 7). Better results were obtained using as catalyst a diarylprolinol-based species containing two dioctylamino residues as substituents in the amino groups. This compound was employed as catalyst, under similar reaction conditions, for the aldol process using acetaldehyde as nucleophile. However, in these transformations the recycling of the catalyst was not explored [140,141].<smiles>[R]N1C(=O)C=CC1=O</smiles>

64<smiles>[R]CC([R])=O</smiles>

3<smiles>[R]C(=O)C([Z2])[C@H]1CC(=O)N([R])C1=O</smiles>

65
(15-76\%, 33-80\% de, $86-96 \%$ ee)

Scheme 7. Michael reaction of maleimides with aldehydes.
Activated methylenes were also used as pro-nucleophiles in the Michael addition using supported catalysts under aqueous conditions. Thus, malonates reacted with $\alpha, \beta$ unsaturated aldehydes $\left(\mathbf{6 6} a, \mathrm{R}^{2}=\mathrm{H}\right)$ using catalyst $\mathbf{5 7}$ in the presence of benzoic acid, in a mixture of water:isopropanol as solvent, affording products 68 (Scheme 8). The catalyst was reused four times with gradual reduction of the yields and enantioselectivities [142].

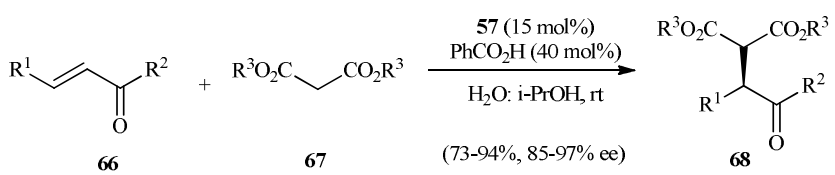

Scheme 8. Michale addition of malonates with $\alpha, \beta$ unsaturated aldehydes.

The catalytic combination 57 (7 mol\%)/ $\mathrm{PhCO}_{2} \mathrm{H}(40$ $\mathrm{mol} \%$ ), in THF/water as solvent, was used for the addition of nitromethane (69) to $\alpha, \beta$-unsaturated aldehydes, yielding products $\mathbf{7 0}$ in high yields (62-82\%) and excellent enantioselectivities (84-94\%). Although the catalyst was recovered and recycled five times, yields sharply decreased after the second cycle, while enantioselectivities dropped gradually [143]. The same trend in recyclability was shown when peptide-supported catalyst 71 (Scheme 9) was used in the addition of nitromethane (69) to $\alpha, \beta$-unsaturated ketones (69-80\%, 90-96\% ee) under similar reaction conditions. This peptide-supported catalyst was also active in the Michael addition of malonates to $\alpha, \beta$-unsaturated ketones under similar reaction conditions $(50-85 \%, 94-97 \%$ ee), and even in a three-component reaction between methacrolein, indole and diisopropyl azodiacarboxylate $(98 \%, 88 \%$ ee) [144]. Better recyclability properties were displayed by the ion tagged $\alpha, \alpha$-diphenyl prolinol catalyst $72(10 \mathrm{~mol} \%)$ in the Michael addition of nitroalkanes to $\alpha, \beta$-unsaturated aldehydes. Products of type $\mathbf{7 0}$ were achieved in high yields (55-95\%) and excellent enantioselectivities (85-94\%) using $96 \%$ aqueous methanol as solvent media. The catalysts was recovered and reused five times without any decrease in product yields and enantioselectivities [145]. 
<smiles></smiles><smiles>CC(C)C[C@H](N)C(=O)O</smiles><smiles>[Y5]OC(c1ccccc1)(c1ccccc1)[C@@H]1C[C@@H](OC(=O)C[n+]2ccn(C)c2)CN1</smiles>

Scheme 9. Supported organocatalyst used in the addition of nitromethane to $\alpha, \beta$-unsaturated aldehydes.

\subsection{Other $\mathrm{C}-\mathrm{C}$ bond forming reactions using supported organocatalysts in aqueous media.}

Although the aldol and Michael addition reactions are probably the most widely studied processes using organocatalysis, other important C-C bond-forming processes have also been explored. Thus, the Morita-BaylisHillman is an organic transformation where a catalyst (usually a tertiary amine or phosphine) promotes the reaction between the $\alpha$-position of an electron-deficient alkene with a carbonyl compound [146,147]. The use of a resin-supported $(S)$-proline in the intramolecular version of this transformation (Scheme 10), working in mixtures of water and several organic solvents, led from low to moderate enantioselectivities, depending highly of the mixture composition. Thus, a mixture of 1,4-dioxane:water (1:1) gave the best yield although low enantioselectivity, whereas a combination of dichloromethane:water (2:1) led to $46 \%$ ee but in poor yield. Furthermore, the absolute configuration of product $\mathbf{7 4}$ resulted reversed in the presence of acetonitrile:water (1:1) [148].<smiles>O=C/C=C/c1ccccc1C=O</smiles>

73

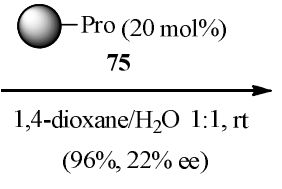

$(96 \%, 22 \%$ ee)
Scheme 10. Morita-Baylis-Hillman catalyzed by resinsupported $(S)$-proline.

More successful was the use of a resin-supported peptide in a Friedel-Crafts-type alkylation $[149,150]$. Thus, several prolyl peptides supported in an amphiphilic polyethyleneglycol-grafted cross-linked polystyrene have been employed as supported catalysts in the alkylation of indoles 76. System 78, having a polyleucine tether, catalyzed the reaction in a mixture of THF:water (1:2), giving, after reduction, products 77 in good yields (57-85\%) and enantioselectivities $(52-88 \%$ ee) [151]. The catalyst was recycled and reused for five cycles with only a slight decrease in yields and enantioselectivities in the fifth cycle. This reaction was also carried out using as catalyst peptidesupported 79, with a $3_{10}$ helical motif (Leu-Leu-Aib) leading to better results $(71-84 \%, 89-91 \%$ ee) when working in neat water $[152,153]$. In addition, catalyst $\mathbf{7 9}$ in combination with a laccase enzyme was also able to catalyze the one-pot Friedel-Crafts alkylation- $\alpha$-oxyamination of indoles, providing the corresponding oxygen-functionalized systems in high selectivities, its recycling being not explored.

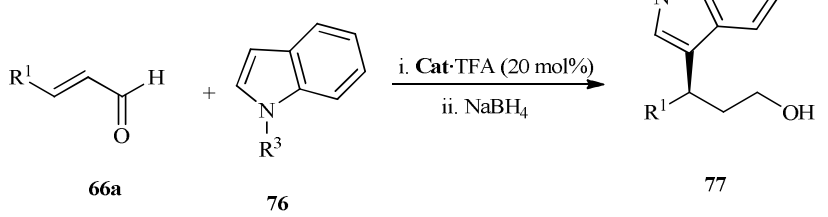

- $(\text { Leu })_{25.4}$-Trp-Trp-Aib-D-Pro-Pro 78

(Aib-Leu-Leu) $)_{2}$-Trp-Trp-Aib-D-Pro-Pro 79

Scheme 11. Friedel-Crafts-type alkylation catalyzed by supported prolyl peptides.

Another seminal reaction that supposed a milestone in the development of organocatalysis as a research field was the Diels-Alder reaction catalyzed by MacMillan's chiral imidazolidine 82 (Scheme 12) [154,155]. Some efforts in order to use this catalyst under homogeneous ionic liquid (imidazolinium $\left[\mathrm{Bmim} \mathrm{PF}_{6}\right.$ or pyridinium [mpy]OTf)/water phase conditions have been carried out affording good results. The use of pyridinium triflate as a ionic liquid allowed its recycle and its reuse for at least three reaction cycles affording similar results $[156,157]$.

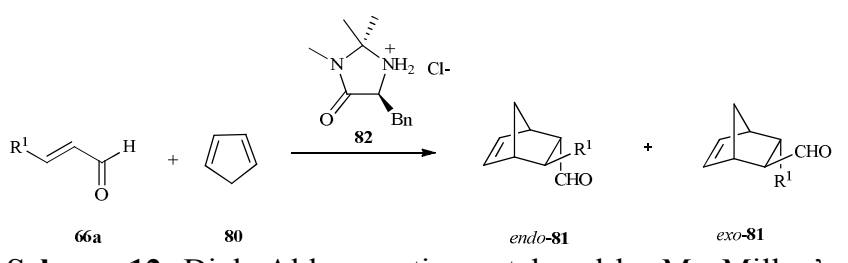

Scheme 12. Diels-Alder reaction catalyzed by MacMillan's chiral imidazolidine.

Higher recyclability was shown by the ionic liquidsupported imidazolidinone 83 (20 mol\%, Figure 19) which was used in the presence of trifluoroacetic acid ( $20 \mathrm{~mol} \%)$ in acetonitrile/water (95:5), being reused five times maintaining its catalytic activity. This catalyst led to the desired products in moderate to good yields (45-99\%) depending of the nature of the $\mathrm{R}^{1}$ substituent, aromatic derivatives affording the best 
results. Although the products were obtained nearly as a 1:1 mixture of endo/exo products, the enantioselectivities for both isomers were consistently high (71-94\%) [158]. In addition, poly(methylhydrosiloxane)-supported chiral imidazolidinone 84 (10 $\mathrm{mol} \%)$, combined to $\mathrm{HBF}_{4}$. was used as catalyst in the Diels-Alder reaction between cyclopentanediene (80) and cinamaldehyde, using as solvent mixtures of organics such as methanol, dichlorometane or acetonitrile with water or even in pure water, the best results being achieved in the latter (98\%, 1:1 endo/exo, 91:90\% ee). However, the best recyclability was obtained in acetonitrile:water (95:5), which allowed it reuse for at least six reaction cycles, the expected mixture of isomers being obtained with up to $92 \%$ ee [159]. Remarkably, a good performance in terms of recyclability was shown using as catalyst a $C_{2}$-symmetric-bypyrrolidine salt derived from $\mathbf{8 5}$ $(10 \mathrm{~mol} \%)$, in the presence of 2 equivalents of $\mathrm{HClO}_{4}$ in water solvent, albeit with moderate enantioselectivities (83$87 \%$ ee). The catalyst was recycled by simple extraction, achieving similar results for the first three cycles (94-95\%, 2.7:1 exo/endo) [160].<smiles>[Y][n+]1ccn(CCCN2C(=O)[C@H](Br)NC2(C)C)c1</smiles>

83

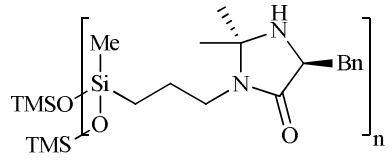

84

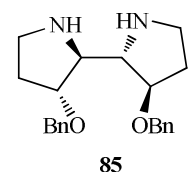

Figure 19. Recyclable organocatalysts used in the DielsAlder reaction.

\subsection{Aqueous oxidation and reduction processes with supported organocatalysts.}

The organocatalytic asymmetric epoxidation of electronpoor alkenes has experienced a significant development in the recent past [161], due to the importance of chiral epoxides as building blocks. The Juliá-Colonna epoxidation is one of the first examples of polypeptide-catalyzed reactions in an aqueous system. Thus, excellent enantioselectivities have been obtained using polyamino acid derivatives such as poly-L-alanine or poly-L-leucine in an organic solvent and an aqueous layer containing $\mathrm{H}_{2} \mathrm{O}_{2}$ and $\mathrm{NaOH}[162,163]$. However, this transformation has several limitations, such as the narrow substrate scope and the long reaction times. Therefore, improved protocols have been developed. For instance, resin-supported peptide 87 (20 mol\%, Scheme 13) promoted the epoxidation of $\alpha, \beta-$ unsaturated aldehydes $66\left(\mathrm{R}^{2}=\mathrm{H}\right)$ in a mixture of THF:water, using $\mathrm{H}_{2} \mathrm{O}_{2}$ as oxidant, affording the final epoxides with high enantioselectivities $(45-87 \%, 74-95 \%$ ee). The introduction of a three amino acid motif with a hydrophobic and bulky aromatic ring was crucial for the activity and selectivity of the reaction. Furthermore, the enantioselectivity of the process was controlled by the absolute configuration of the terminal proline residue. The recovery of the peptide was easily accomplished by filtration, and the enantioselectivity was maintained after several reaction runs, but the rate decreased after the second cycle [164]. In addition, moderate results were achieved using as catalyst sulfur-functionalized chiral ionic liquid $\mathbf{8 8}$ $(10 \mathrm{~mol} \%)$ in the presence of $\mathrm{Na}_{2} \mathrm{CO}_{3}$ as a base in water as solvent in the epoxidation of $\alpha, \beta$-unsaturated aldehydes $\mathbf{6 6}$ $\left(\mathrm{R}^{2}=\mathrm{H}\right)(41-57 \%, 70-72 \%$ ee). Since the organocatalyst was insoluble in ether and soluble in water, it could be easily separated from the products and reused for at least five times without detrimental of the activity [165].

Chiral phase-transfer reagents, especially those derived from Cinchona alkaloids, have also been applied to this transformation under mild reaction conditions, achieving high efficiency. However, only moderate enantioselectivities $(55-93 \%, 19-86 \%$ ee) were obtained in the epoxidation of (E)-diarylenones $\left(66, \mathrm{R}^{1}=\mathrm{Ar}^{1}, \mathrm{R}^{2}=\mathrm{Ar}^{2}\right)$ using soluble chiral polymeric ammonium salts anchored to diacetamidoPEG2000 chloride resins, such as $\mathbf{8 9}$, as organocatalysts (5 mol\%, Scheme 13 ), using $t-\mathrm{BuOOH}$ as oxidant in a biphasic system of dichloromethane and aqueous $\mathrm{KOH}(1 \mathrm{M})$. The catalyst was precipitated with ether after the reaction and reused for three times without losing its activity [166].

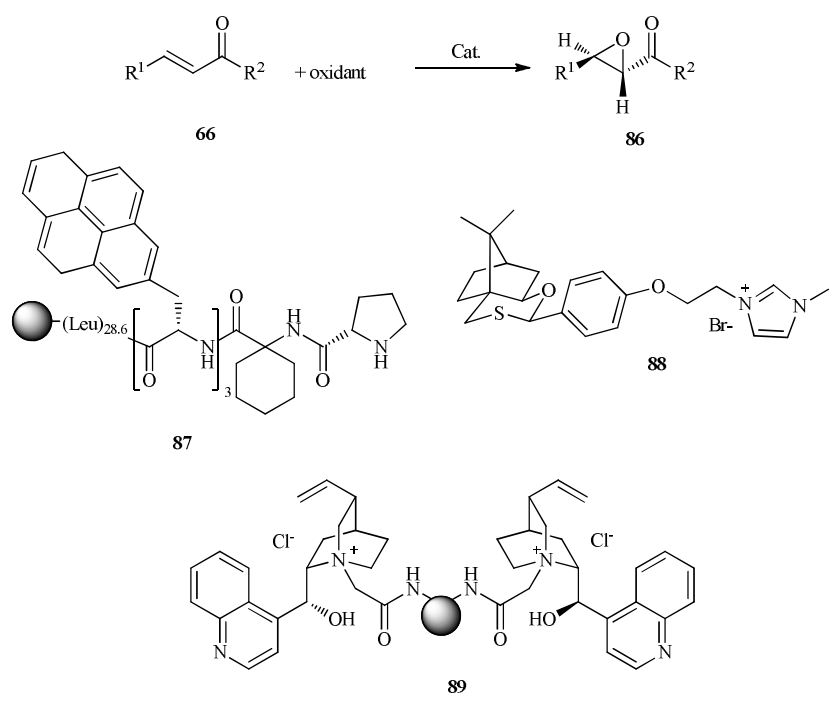

Scheme 13. Organocatalytic asymmetric epoxidation of electron-poor alkenes.

The enantioselective $\alpha$-oxyamination of aldehydes 90a $\left(\mathrm{R}^{2}=\mathrm{CHO}\right)$, using 2,2,6,6-tetramethylpiperidine-1-oxyl (TEMPO) involves the oxidation of an enamine by a single electron transfer (SET) mechanism forming a planar radical cation. This radical undergoes an enantioface-selective $\mathrm{C}-\mathrm{O}$ bond formation with TEMPO. In addition, iron trichloride (30 mol\%) was used as SET reagent in the $\alpha$-oxyamination of aldehydes, using as catalyst a resin-supported peptide $(93, \mathrm{n}=25.4,20 \mathrm{~mol} \%)$ in the presence of sodium nitrate. After in situ reduction with $\mathrm{NaBH}_{4}$, the $\alpha$-oxygenated product 91a $\left(\mathrm{R}^{2}=\mathrm{CH}_{2} \mathrm{OH}\right)$ was obtained in good yields and enantioselectivities $(73-84 \%, 87-93 \%$ ee), working in a 
mixture THF:water (1:2) as solvent [167]. The procedure was extended to a one-pot sequential reaction, starting from primary alcohols, using copper(I) chloride under aerobic conditions. Hence, catalyst $93(\mathrm{n}=25.4,20 \mathrm{~mol} \%), \mathrm{CuCl}$ (30 $\mathrm{mol} \%$ ) and 2,2'-bipyridine (30 $\mathrm{mol} \%$ ), in the presence of oxygen and in a mixture of THF:water as solvent (1:2) led to the formation of products $92\left(\mathrm{R}^{2}=\mathrm{CH}_{2} \mathrm{OH}\right)$ in good results $(66-85 \%, 4-93 \%$ ee). The catalyst was recovered by filtration and reused for seven times without a substantial loss in both yields and enantioselectivities [168]. On the other hand, the combination of a peptide-supported catalyst with an enzymatic air oxidation using laccase enzyme, avoids the use of any metal reagent. So, catalyst 93 ( $\mathrm{n}=27,20 \mathrm{~mol} \%$ ), combined to enzyme laccase in a acetate buffer solution $(\mathrm{pH}$ 4.4) and in the presence of air, afforded aldehydes $92 \mathrm{~b}\left(\mathrm{R}^{2}=\right.$ $\mathrm{CHO}$ ), while the addition of the surfactant Tween 80 to the reaction mixture, led to the corresponding carboxylic acids 92c $\left(\mathrm{R}^{2}=\mathrm{CO}_{2} \mathrm{H}\right)$. In both protocols, good yields $(65-80 \%)$ and enantioselectivities (86-92\% ee) were achieved [169].

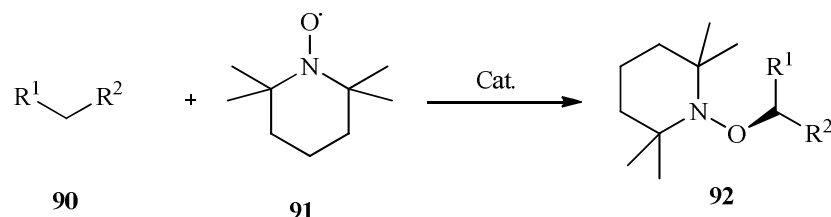

$\mathcal{-}_{(\mathrm{Leu})_{\mathrm{n}}-\mathrm{Tr} p-\text { Trp-Aib-D-Pro-Pro }}$

93

Scheme 14. Enantioselective $\alpha$-oxyamination catalyzed by resin-supported peptide.

Finally, the resin-peptide supported catalyst $\mathbf{9 3}$, as its trifluoroacetic salt (Scheme 15), was used as catalyst for the hydrogen transfer hydrogenation reaction of unsaturated aldehydes 94 in aqueous media, using Hantzsch ester 95 as reducting species. The presence of a hydrophobic leucine chain was essential for both reactivity and selectivity, providing a hydrophobic microenvironment around the terminal proline residue. However, the possible recovery of the catalyst was not investigated [170,171].<smiles>[Y]C(C)=CC=O</smiles>

-(Leu) $25.4-$ Trp-Trp- Aib-D-Pro-Pro -TFA

93-TFA

Scheme 15. Resin-peptide supported catalyst used in the hydrogen transfer hydrogenation.

\section{CONCLUSIONS}

Although supported reagents have been in use for decades, in the last years are experiencing a surge in popularity due to the discovery of an array of different materials and nanoparticles suitable to anchoring catalysts, thus allowing its recovery. As stereoselective organocatalysis is perhaps the present synthetic methodology which more easily and efficiently allows the preparation of interesting enantioenriched products, anchoring organocatalysts to different supports represents a further step of increasing the efficiency of organocatalyzed processes. These reactions are usually performed using rather large catalyst loadings, therefore the easy recovery of the organocatalyst present obvious economic advantages, as well as facilitates their possible use in convenient continuous flow systems. If these methodologies can be carried out in a cheap and environmentally convenient solvent as water, they can be considered as almost perfect. This review has shown that many efforts have been devoted in the last years in order to develop easily recyclable and reusable chiral organocatalyst suitable to develop their stereoselective activity in aqueous media. In many cases the obtained results, concerning stereoselectivity and recyclability have been impressive, although still plenty of research is necessary. Thus, the aldol and Michael reactions have been profusely studied, but many processes remain practically or totally unexplored. There is no doubt that new anchored organocatalysts with higher reactivity in water will be developed, and that many more synthetic procedures involving all these reagents will show in near future.

\section{CONFLICT OF INTEREST}

The authors confirm that this article content has no conflictof interest.

\section{ACKNOWLEDGEMENTS}

This work was financially supported by the University of Alicante (VIGROB-173, GRE12-03, UAUSTI13-01, UAUSTI13-02).

\section{REFERENCES}

[1] Noyori, R. Pursuing practical elegance in chemical synthesis. Chem. Commun., 2005, 1807-1811.

[2] Drauz, K.; Gröger, H.; May, O. Enzyme Catalysis in Organic Synthesis, $3^{\text {rd }}$ ed.; Wiley-VCH Verlag, Weinheim, 2012.

[3] Kerton, F.; Marriott, R. Alternative Solvents for Green Chemistry, $2^{\text {nd }}$ ed.; RSC Publishing, Cambridge, 2013.

[4] P. T. Anastas and J. C. Warner, Green Chemistry, Theory and Practice, $1^{\text {st }}$ Ed. Oxford University Press, Oxford, 1998.

[5] Marteel-Parrish, A. E; Martin A. A. Green Chemistry and Engineering: A Pathway to Sustainability, $1^{\text {st }}$ ed. John Wiley \& Sons, New Jersey, 2014.

[6] Christmann, M.; Bräse S. Asymmetric Synthesis: The Essentials. $2^{\text {nd }}$ Ed. Wiley-VCH: Weinheim, 2007.

[7] Ojima, I. Catalytic Asymmetric Synthesis, $3^{\text {rd }}$ Ed. John Wiley \& Sons, New Jersey, 2010

[8] Li, C.-J.; Chen, L. Organic Chemistry in Water, Chem. Soc. Rev. 2006, 35, 68-82.

[9] Reichardt, C.; Welton, T. Solvents and Solvent Effects in Organic Chemistry. $4^{\text {th }}$ ed. Wiley-VCH Verlag, Weinheim, 2011.

[10] Dalko P. I. Enantioselective Organocatalysis: Reactions and Experimental Procedures, $1^{\text {st }}$ ed. Wiley-VCH Verlag, Weinheim, 2007.

[11] Mahrwald, R Enantioselective Organocatalyzed Reactions, $1^{\text {st }}$ Ed. Springer: Heidelberg, 2011; Vols 1 and 2;

[12] List, B. Maruoka, K. Science of Synthesis, $1^{\text {st }}$ ed. Georg Thieme Verlag, Stuttgart, 2011; Vols 1 and 2. 
[13] Dalko, P. I. Comprehensive Enantioselective Organocatalysis: Catalysis, Reactions and Applications, $1^{\text {st }}$ ed. Wiley-VCH Verlag, Weinheim, 2013.

[14] Giacalone, F.; Gruttadauria, M. In Comprehensive Enantioselective Organocatalysis: Catalysis, Reactions and Applications, Dalko, P. I. Wiley-VCH Verlag, Weinheim, 2013, Vol. II, pp 673-717.

[15] Narayan, S.; Muldoon, J.; Finn, M G.; Fokin, V. V.; Kolb, H. C.; Sharpless, K. B. "On water": unique reactivity of organic compounds in aqueous suspension, Angew. Chem. Int. Ed. 2005, 44, 3275-3279.

[16] Hayashi, Y. In water or in the presence of water? Angew. Chem. Int. Ed. 2006, 45, 8013-8104.

[17] Blackmond, D. G.; Armstrong, A.; Coombe, V.; Wells, A. Water in organocatalytic processes: debunking the myths, Angew. Chem. Int. Ed. 2006, 45, 3798-3800.

[18] Nyberg, A. I.; Usano, A.; Pihko, P. M. Proline-catalyzed ketonealdehyde aldol reactions are accelerated by water. Synlett 2004, 1891-1896.

[19] Pihko, P. M.; Laurikainen, K. M.; Usano, A.; Nyberg, A. I.; Kaavi, J. A. Effect of additives on the proline-catalyzed ketone-aldehyde aldol reactions. Tetrahedron 2006, 62, 317-328.

[20] Zotova, N.; Franzke, A.; Armstrong, A.; Blackmond, D. G. Clarification of the role of water in proline-mediated aldol reactions. J. Am. Chem. Soc., 2007, 129, 15100-15101.

[21] Jung, Y.; Marcus, R. A. On the theory of organic catalysis "on water", J. Am. Chem. Soc., 2007, 129, 5492-5502.

[22] Zhang, L., Cui, L., Luo, S.; Cheng, J.-P. In Green Techniques for Organic Synthesis and Medicinal Chemistry W.; Cue, B. W. Eds.; John Wiley \& Sons, Ltd, Chichester, 2012, pp 99-135.

[23] Shaikh, I. R. Organocatalysis: key trends in green synthetic chemistry, challenges, scope towards heterogenization, and importance from research and industrial point of view, J. Catal. 2014, 1-35.

[24] Kristensen, T. E.; Hansen, T. In Comprehensive Enantioselective Organocatalysis: Catalysis, Reactions and Applications, Dalko, P. I. Wiley-VCH Verlag, Weinheim, 2013, Vol. II, pp 651-672.

[25] Siyutkin, D. E.; Kucherenko, A. S.; Zlotin, S. G. In Comprehensive Enantioselective Organocatalysis: Catalysis, Reactions and Applications, Dalko, P. I. Wiley-VCH Verlag, Weinheim, 2013, Vol. II, pp 617-650.

[26] Wurtz, C. A. "Ueber einen Aldehyd-Alkohol". J. Prak. Chem. 1872, 5, 457-464.

[27] Mahrwald, R. Modern Aldol Reactions, $1^{\text {st }}$ Ed. Wiley-VCH: Weinheim, 2004, Vols. 1-2.

[28] Trost, B. M.; Brindle, C. S. The direct catalytic asymmetric aldol reaction. Chem. Soc. Rev. 2010,39, 1600-1632.

[29] Mahrwald, R. Methods in Stereoselective Aldol Reactions, $1^{\text {st }}$ Ed.; Wiley-VCH: Weinheim, 2013.

[30] Fessner, W.-D. In Asymmetric Organic Synthesis with Enzymes, Gotor, V., Alfonso, I., Garcia-Urdiales, E. Eds, Wiley-VCH: Weinheim, 2008, pp. 275-318.

[31] Greenberg, W.A. In Biocatalysis for the Pharmaceutical Industry, Tao, J.; Lin, G.-Q.; Liese, A. Eds., Wiley-VCH: Weinheim, 2009, pp. 111-119.

[32] Guillena, G.; Nájera, C.; Ramón, D. J. Enantioselective direct aldol reaction: the blossoming of modern organocatalysis. Tetrahedron Asymmetry, 2007, 18, 2249-2293.

[33] Geary, L. M.; Hultin, P. G. The state of the art in asymmetric induction: the aldol reaction as a case study. Tetrahedron: Asymmetry 2009, 20, 131-173.

[34] Zlotin, S. G.; Kucherenko, A. S.; Beletskaya, I. P. Organocatalysis of asymmetric aldol reaction. Catalysts and reagents. Russ. Chem. Rev., 2009, 78, 737-784.

[35] Guillena, G. in Enantioselective Organocatalyzed Reactions II, Mahrwald, R., Ed.; Springer, Dordrecht 2011, pp 245-342.

[36] Guillena, G. In: Modern Methods in Stereoselective Aldol Reactions. Mahrwald, R., Ed.; Wiley-VCH: Weinheim; 2013, pp. 155-268.

[37] Eder, U.; Sauer, G.; Wiechert, R. New type of asymmetric cyclization to optically active steroid CD partial structures. Angew. Chem. Int. Ed. Engl., 1971, 10, 496-497.

[38] Hajos, Z.G.; Parrish, D. R. Asymmetric synthesis of bicyclic intermediates of natural product chemistry. J. Org. Chem., 1974, $39,1615-1621$.
[39] Hajos, Z. G.; Parrish, D. R. In: Organic Synthesis; Freeman, J. P., Ed.; John Wiley \& Sons: New York; 1990, Vol. VII, pp. 363-368.

[40] Buchschacher, P.; Fürst, A.; Gutzwiller, J. In: Organic Synthesis; Freeman, J.P., Ed.; John Wiley \& Sons: New York; 1990; Vol. VII, pp. 368-372.

[41] Kwiatkowski, S.; Syed, A.; Brock, C. P.; Watt, D. S. Enantioselective synthesis of (-)-(7aS)-2,3,7,7a-tetrahydro-7aphenylthio- $1 H$-indene-1,5(6H)-dione and (+)-(8aS)-3,4,8,8atetrahydro-8a-phenylthio-1,6(2H,7H)-naphthalenedione. Synthesis, 1989, 818-820

[42] Tietze, L. F.; Utecht, J. Improved preparation of enantiomerically pure $(+)-(4 \mathrm{a} S, 5 S)-5$-tert-butoxy-4a-methyl-4,4a,5,6,7,8-hexahydro2(3H)-naphthalenone. Synthesis, 1993, 957-958.

[43] List, B.; Lerner, R. A.; Barbas, C. F., III. Proline-catalyzed direct asymmetric aldol reactions. J. Am. Chem. Soc., 2000, 122, $2395-$ 2396.

[44] List, B.; Pojarliev, P.; Castello, C. Proline-catalyzed asymmetric aldol reactions between ketones and $\alpha$-unsubstituted aldehydes. Org. Lett., 2001, 3, 573-575.

[45] Sakthivel, K.; Notz, W.; Bui, T.; Barbas, C. F., III. Amino acid catalyzed direct asymmetric aldol reactions: a bioorganic approach to catalytic asymmetric carbon-carbon bond-forming reactions. $J$. Am. Chem. Soc., 2001, 123, 5260-5267.

[46] Hernández, J. G.; Juaristi, E. Recent efforts directed to the development of more sustainable asymmetric organocatalysis. Chem. Commun., 2012, 48, 5396-5409.

[47] Bañón-Caballero, A.; Guillena, G.; Nájera, C. Solvent-free enantioselective organocatalyzed aldol reactions. Mini Rev. Org, Chem. 2014, 11, 118-128.

[48] Mlynarski, J.; Paradowska, J. Catalytic asymmetric aldol reactions in aqueous media, Chem. Soc. Rev., 2008, 37, 1502-1511.

[49] Mlynarski, J.; Baś, Catalytic asymmetric aldol reactions in aqueous media- a 5 year update. Chem. Soc. Rev. 2014 43, 577-587.

[50] Bartók, M.; Dombi, G. Organocatalytic asymmetric aldol reactions in aqueous or neat conditions: review of data published in 20092013. Curr. Green. Chem. 2014, 1, 191-201.

[51] Groselj, U.; Seebach, D; Badine, D. M.; Schweizer, W. B.; Beck A. K.; Krossing, I.; Klose, P.; Hayashi, Y.; Uchimaru, T. Structures of the Reactive Intermediates in Organocatalysis with Diarylprolinol Ethers. Helvetica Chim. Acta 2009, 92, 1225-1259.

[52] Aratake, S.; Itoh, T.; Okano, T.; Nagae, G.; Sumiya, T.; Shoji, M.; Hayashi, Y. Highly Diastereo- and Enantioselective Direct Aldol Reactions of Aldehydes and Ketones Catalyzed by Siloxyproline in the Presence of Water. Chem. Eur. J., 2007, 13, 10246-10256.

[53] Sapkale, P.; Sahu, M.; Chaudhari, M.; Patil, P. R. Trends of click synthesis: a review. Int. J. Pharm. Pharm. Sci. 2014, 6, 99-103.

[54] Heravi, M. M.; Hamidi, H.; Zadsirjan, V. Recent Applications of Click Reaction in the Syntheses of 1,2,3-triazoles. Curr. Org. Synth. 2014, 11, 647-675.

[55] Lowe, A. B. Thiol-ene "click" reactions and recent applications in polymer and materials synthesis: a first update. Polym. Chem 2014, 5, 4820-4870.

[56] Font, D., Jimeno, C.; Pericàs, M. A. Polystyrene-supported hydroxyproline: an insoluble, recyclable organocatalyst for the asymmetric aldol reaction in water. Org. Lett. 2006, 8, 4653-4655.

[57] Cambeiro, X., C.; Martín-Rapún, R.; Miranda, P. O..; Sayalero, S.; Alza, E.; Llanes, P.; Pericàs, M. A. Continuous-flow enantioselective $\alpha$-aminoxylation of aldehydes catalyzed by a polystyrene-immobilized hydroxyproline. Beilstein. J. Org. Chem. 2011, 7, 1486-1493.

[58] Font, D., Sayalero, S.; Bastero, A.; Jimeno, C.; Pericàs, M. A Toward an artificial aldolase. Org. Lett. 2008, 10, 337-340.

[59] Ayats, C.; Henseler, A. H.; Pericàs, M. A. A solid-supported organocatalyst for continuous-flow enantioselective aldol reactions. ChemSusChem 2012, 5, 320-325.

[60] Sagamanova, I. K.; Sayalero, S.; Martínez-Arranz, S.; Albéniz, A. C.; Pericàs, M. A. Asymmetric organocatalysts supported on vinyl addition polynorbornenes for work in aqueous media. Catal. Sci. Technol. 2015, 5, 754-764

[61] Giacalone, F.; Gruttadauria, M.; Mossuto Marculescu, A.; Noto, R. Polystyrene-supported proline and prolinamide. Versatile heterogeneous organocatalysts both for asymmetric aldol reaction in water and $\alpha$-selenenylation of aldehydes. Tetrahedron: Lett. 2007, 48, 255-259. 
[62] Gruttadauria, M.; Giacalone, F.; Mossuto Marculescu, A.; Lo Meo, P.; Riela, S.; Noto, R. Hydrophobically directed aldol reactions: polystyrene-supported L-proline as a recyclable catalyst for direct asymmetric aldol reactions in the presence of water. Eur. J. Org. Chem. 2007, 4688-4698.

[63] Gruttadauria, M.; Giacalone, F.; Mossuto Marculescu, A.; Noto, R. Novel prolinamide-supported polystyrene as highly stereoselective and recyclable organocatalyst for the aldol reactions. Adv. Synth. Catal. 2008, 350, 1397-1405.

[64] Gruttadauria, M.; Giacalone, F.; Mossuto Marculescu, A.; Pia Salvo, A. M.; Noto, R. Stereoselective aldol reaction catalyzed by a highly recyclable polystyrene supported substituted prolinamidecatalyst. Arkivoc. 2009, viii, 5-15.

[65] Liu, Y.-X.; Sun, Y.-N.; Tan, H.-H.; Liu, W.; Tao, J.-C. Linear polystyrene anchored L-proline, new recyclable organocatalysts for the aldol reaction in the presence of water. Tetrahedron: Asymmetry 2007, 18, 2649-2656.

[66] Liu, Y.-X.; Sun, Y.-N.; Tan, H.-H.; Tao, J.-C. Asymmetric aldol reaction catalyzed by a new polystyrene-supported L-proline in the presence of water. Catal. Lett. 2008, 120, 281-287.

[67] Kristensen, T. E.; Vestli, K.; Frediksen, K. A.; Hansen, F. K.; Hansen, T. Synthesis of acrilic polymer beads for solid-supported proline-derived organocatalysts. Org. Lett. 2009, 11, 2968-2971.

[68] Rulli, G.; Frediksen, K. A.; Duangdee, N.; Bonge-Hansen, T.; Berkessel, A.; Gröger, H. Asymmetric organocatalytic aldol reaction in water: mechanistic insights and development of a semicontinuously operating process. Synthesis, 2013, 45, 2512-2519.

[69] Guillena, G.; Hita, M. C.; Nájera, C. BINAM-prolinamides as recoverable catalysts in the direct aldol condensation. Tetrahedron Asymmetry, 2006, 17, 729-733.

[70] Gryko, D.; Kowalczyk, B.; Zawadzki, L. Bisprolinediamides with the binaphthyl backbone as organocatalysts for the direct asymmetric aldol reaction. Synlett, 2006, 1059-1062.

[71] Guillena, G.; Hita, M. C.; Nájera, C. High acceleration of the direct aldol reaction cocatalyzed by BINAM-prolinamides and benzoic acid in aqueous media. Tetrahedron Asymmetry, 2006, 17, 14931497.

[72] Guizzetti, S.; Benaglia, M.; Pignataro, L.; Puglisi, A. A multifunctional proline-based organic catalyst for enantioselective aldol reactions. Tetrahedron Asymmetry, 2006, 17, 2754-2760.

[73] Ma, G.-N.; Zhang, Y.-P.; Shi, M. L-Proline diamides with an axially chiral binaphthylene backbone as efficient- organocatalysts for direct asymmetric aldol reactions: the effect of acetic acid. Synthesis, 2007, 197-208.

[74] Guizzetti, S.; Benaglia, M.; Raimondi, L.; Celentano, G. Enantioselective direct aldol reaction "on water" promoted by chiral organic catalysts. Org. Lett., 2007, 9, 1247-1250

[75] Guillena, G.; Hita, M. C.; Nájera, C. Organocatalyzed direct aldol condensation using L-proline and BINAM-prolinamides: regio-, diastereo-, and enantioselective controlled synthesis of 1,2-diols. Tetrahedron Asymmetry, 2006, 17, 1027-1031.

[76] Guillena, G.; Hita, M. C.; Nájera, C. Highly selective direct aldol reaction organocatalyzed by $(S)$-BINAM-L-prolinamide and benzoic acid using $\alpha$-chalcogen-substituted ketones as donors. ARKIVOC, 2007, iv, 260-269.

[77] Guillena, G.; Hita, M. C.; Nájera, C. $\alpha$-Chloroacetone as a donor in the BINAM-L-prolinamide organocatalyzed aldol reaction: application to the enantioselective synthesis of $\alpha, \beta$-epoxy ketones. Tetrahedron: Asymmetry, 2007, 18, 1272-1277.

[78] Kucherenko, A. S.; Syutkin, D. E.; Zlotin, S. G. Asymmetric aldol condensation in an ionic liquid-water system catalyzed by $(S)$ prolinamide derivatives. Russ. Chem. Bull., 2008, 57, 591-594.

[79] Bañón-Caballero, A.; Guillena, G.; Nájera, C. Solvent-free direct enantioselective aldol reaction using polystyrene-supported $\mathrm{N}$ sulfonyl-(Ra)-binam-D-prolinamide as a catalyst. Green Chem. 2010, 12, 1599-1606.

[80] Bañón-Caballero, A.; Guillena, G.; Nájera, C. Cross-linkedpolymer-supported $N-\left\{2^{\prime}-[(\right.$ arylsulfonyl)amino][1,1'binaphthalen]-2-yl $\}$ prolinamide as organocatalyst for the direct aldol intermolecular reaction under solvent-free conditions. Helv. Chim. Acta, 2012, 95, 1831-1841.

[81] Pedrosa, R.; Andrés, J. M.; Gamarra, A.; Manzano, R.; PérezLópez, C. Novel sulfonylpolystyrene-supported prolinamides as catalysts for enantioselective aldol reaction in water. Tetrahedron, 2013, 69, 10811-10819.
[82] Bradshaw, B.; Bonjoch, J. The Wieland-Miescher ketone: a journey from organocatalysis to natural product synthesis. Synlett, 2012, 337-356.

[83] Pedrosa, R.; Andrés, J. M.; Manzano, R.; Pérez-López, C. Novel supported prolinamides as organocatalyst for enantioselective cyclization of triketones. Tetrahedron Lett., 2013, 54, 3101-3104.

[84] Li, J.; Yang, G.; Cui, Y. Recyclable polyvinyl chloride-supported pyrrolidine-thiourea as a bifunctional organocatalyst for direct asymmetric aldol reaction in aqueous media. J. Appl. Polym. Sci. 2011, 121 , 1506-1511.

[85] Zhang, X.; Zhao, W.; Yang, G.; Cui, Y. Polyvinylidene chloridesupported L-prolineamide as a recoverable catalyst for asymmetric aldol reaction between ketone and aromatic aldehydes. J. Appl. Polym. Sci., 2013, 127, 3537-3542.

[86] Zhang, X.; Zhao, W.; Zou, J.; Liu, Y.; Li, R.; Cui, Y. Aldol reaction catalyzed by a hydrophilic catalyst in aqueous micelle as an enzyme mimic system. Chirality, 2009, 21, 492-496.

[87] Henseler, A. H.; Ayats, C.; Pericàs, M. A. An enantioselective recyclable polystyrene-supported threonine-derived organocatalyst for aldol reactions. Adv. Synth. Catal., 2014, 356, 1795-1802.

[88] Akagawa, K.; Sakamoto, S. Kudo, K. Direct asymmetric aldol reaction in aqueous media using polymer-supported peptide. Tetrahedron Lett., 2005, 46, 8185-8187.

[89] Zhou, J.; Wan, J. Ma, X.; Wang, W. Copolymer-supported heterogeneous organocatalyst for asymmetric aldol addition in aqueous medium. Org. Biomol. Chem., 2012, 10, 4179-4185.

[90] Rostamnia, S.; Doustkhah, E. Nanoporous silica-supported organocatalyst: a hetereogeneous and green hydrib catalyst for organic transformations. RSC Adv., 2014, 4, 28238-28248.

[91] Monge-Marcet, A., Pleixats, R., Cattoën, X.; Wong Chi Man, M.; Alonso, D. A.; Nájera, C. Prolinamide bridged silsesquioxane as an efficient, eco-compatible and recyclable organocatalyst. New J. Chem., 2011, 35, 2766-2772.

[92] Monge-Marcet, A., Cattoën, X.; Alonso, D. A.; Nájera, C.; Wong Chi Man, M.; Pleixats, R. Recyclable silica-supported prolinamide organocatalysts for direct asymmetric aldol reaction in water. Green Chem., 2012, 14, 1601-1610.

[93] Doyagüez, E. G.; Calderón, F.; Sánchez, F.; Fernández-Mayoralas, A. Asymmetric aldol reaction catalyzed by a heterogenized proline on a mesoporous support. The role of the nature of solvents. J. Org. Chem., 2007, 72, 9353-9356.

[94] Bañón-Caballero, A.; Guillena, G.; Nájera, C.; Faggi, E.; Sebastián, R.,M.; Vallribera, A. Recoverable silica-gel supported binamprolinamides as organocatalysts for the enantioselective solventfree intra- and intermolecular aldol reaction. Tetrahedron, 2013, 69, 1307-1315.

[95] Bañón-Caballero, A.; Guillena, G.; Nájera, C. Solvent-free enantioselective Friëdlander condensation with wet 1,1'binaphthalene-2,2'-diamine-derived prolinamides organocatalysts. J. Org. Chem., 2013, 78, 5349-5356.

[96] Mrówczyński, R.; Nan, A.; Liebscher, J. Magnetic nanoparticlesupported organocatalysts: an efficient way of recycling an reuse. RSC Adv., 2014, 4, 5927-5952.

[97] Luo, S.; Zhenga, X.; Cheng, J-P. Asymmetric bifunctional primary aminocatalysis on magnetic nanoparticles. Chem. Commun., 2008, 5719-5721.

[98] Wan, J.; Ding, L.; Wu, T.; Ma, X.; Tang, Q. Facile one-pot fabrication of magnetic nanoparticles (MNPs)-supported organocatalysts using phosphonates as an anchor point through direct co-precipitation method. RSC Adv., 2014, 4, 38323-38333.

[99] Wang, W.; Ma, X.; Wan, J.; Cao, J.; Tang, Q. Preparation and confinement effect of a heterogeneous 9-amino-9-deosy-epicinchonidine organocatalyst for asymmetric aldol addition in aqueous medium. Dalton Trans., 2012, 41, 5715-5726.

[100] Calogero, S.; Lanari, D.; Orrú, M.; Piermatti, O.; Pizzo, F.; Vaccaro, L. Supported L-proline on zirconium phosphates methyl and/or phenyl phosphonates as heterogeneous organocatalysts for direct asymmetric aldol addition. J. Catal., 2011, 282, 121-119.

[101] Qiao, Y.; Headley, A. D. Ionic liquid immobilized organocatalysts for asymmetric reaction in aqueous media. Catalysts, 2013, 3, 709725 .

[102] Luo, S.; Mi, X.; Zhang, L.; Liu, S.; Xu, H.; Cheng, J.-P. Functionalized ionic liquids catalyzed direct aldol reactions. Tetrahedron, 2007, 63, 1923-1930. 
[103] Siyutkin, D. E.; Kucherenko, A. S.; Struchkova, M. I.; Zlotin, S. G. A novel $(S)$-proline-modified task-specific chiral ionic liquid-an amphiphilic recoverable catalyst for direct asymmetric aldol reactions in water. Tetrahedron Lett., 2008, 49, 1212-1216.

[104] Siyutkin, D. E.; Kucherenko, A. S.; Zlotin, S. G. Hydroxy- $\alpha$-amino acids modified by ionic liquid moieties: recoverable organocatalysts for asymmetric aldol reactions in the presence of water. Tetrahedron, 2009, 65, 1366-1372.

[105] Lombardo, M.; Pasi, F.; Easwar, S.; Trombini, C. Direct asymmetric aldol reaction catalyzed by an imidazolium-tagged trans-4-hydroxy-L-proline under aqueous biphasic conditions. Synlett, 2008, 2471-2474.

[106] Lombardo, M.; Easwar, S.; Pasi, F.; Trombini, C. The ion Tag strategy as a route to highly efficient organocatalysts for the direct asymmetric aldol reaction. Adv. Synth. Catal., 2009, 351, 276-282.

[107] Lombardo, M.; Easwar, S.; De Marco, A.; Pasi, F ; Trombini, C. A modular approach to catalyst hydrophobicity for an asymmetric aldol reaction in a biphasic aqueous environment. Org. Biomol. Chem., 2008, 6, 4224-4229.

[108] Siyutkin, D. E.; Kucherenko, A. S.; Zlotin, S. G. A novel $(S)$ prolinamide modified by ionic liquid moiety: a high performance recoverable catalyst for asymmetric aldol reactions in aqueous media. Tetrahedron, 2010, 66, 513-518.

[109] Kochetkov, S. V..; Kucherenko, A. S.; Zlotin, S. G. $(1 R, 2 R)-$ $\operatorname{Bis}[(S)$-prolinamido]cyclohexane modified with ionic groups: the first $C_{2}$-symmetric immobilized organocatalyst for asymmetric aldol reactions in aqueous media. Eur. J. Org. Chem., 2011, 61286133.

[110] Kochetkov, S. V.; Kucherenko, A. S.; Kryshtal, G. V.; Zhdankina, G. M.; Zlotin, S. G. Simple ionic liquid supported $C_{2}$-symmetric bisprolinamides as recoverable organocatalysts for the asymmetric aldol reactions in the presence of water. Eur. J. Org. Chem., 2012, 7129-7134.

[111] Kong, Y., Tan, R.; Zhao, L. Yin, D. L-Proline supported on ionic liquid-modified magnetic nanoparticles as a highly efficient and reusable organocatalyst for direct asymmetric aldol reaction in water. Green Chem., 2013, 15, 2422-2433

[112] Montroni, E.; Lombardo, M.; Quintavalla, A.; Trombini, C.; Gruttadauria, M.; Giacalone, F. A liquid-liquid biphasic homogeneous organocatalytic aldol protocol based on the use of a silica gel bound multilayered ionic liquid phase. ChemCatChem, 2012, 4, 1000-1006

[113] Zhang, X.; Zhao, W.; Qu, C.; Yang, L.; Cui, Y. Efficient asymmetric aldol reaction catalyzed by polyvinylidine chloridesupported ionic liquid/L-proline catalyst system. Tetrahedron: Asymmetry, 2012, 23, 468-473.

[114] Caminade, A. M.; Ouali, A.; Keller, M.; Majoral, J.-P. Organocatalysis with dendrimers. Chem. Soc. Rev., 2012, 41, 41134125 .

[115] Rasmussen, B.; Christensen, J. B. Organocatalytic dendrimers. Org. Biomol. Chem., 2012, 10, 4821-4835.

[116] Wang, D.; Astruc, D. Dendritic catalysis-Basic concepts and recent trends. Coord. Chem. Rev., 2013, 257, 2317-2334.

[117] Wu, Y.; Zhang, Y.; Yu, M.; Zhao, G.; Wang, S. Highly efficient and reusable dendritic catalysts derived from $N$-prolylsulfonamide for the asymmetric direct aldol reaction in water. Org. Lett., 2006 , $8,4417-4420$

[118] Lo, C.-M.; Chow, H.-F. Structural Effects on the Catalytic, Emulsifying, and Recycling Properties of Chiral Amphiphilic Dendritic Organocatalysts J. Org. Chem., 2009, 74, 5187-5191.

[119] Kofoed, J.; Darbre, T., Reymond, J.-L. Artificial aldolase from peptide dendrimer combinatorial libraries. Org. Biomol. Chem., 2006, 6, 3268-3281.

[120] Alonso, D. A. Organocatalyzed Conjugate Additions in Enantioselective Organocatalyzed Reactions II. Asymmetric C-C Bond Formation Processes. Mahrwald, R., Ed.; Wiley-VCH: Weinheim; 2013, pp. 41-185.

[121] Roux, C.; Bressy, C. In Comprehensive Enantioselective Organocatalysis: Catalysis, Reactions and Applications, Dalko, P. I. Ed. Wiley-VCH Verlag, Weinheim, 2013, Vol. III, pp 10131042

[122] Rios, R.; Companyo, X. In Comprehensive Enantioselective Organocatalysis: Catalysis, Reactions and Applications, Dalko, P. I. Ed. Wiley-VCH Verlag, Weinheim, 2013, Vol. III, pp 977-1012.
[123] Chen, F.; Gong, P.; Gao, Y.; Zhang, H.; Zhou, A. Asymmetric organocatalytic Michael additions in aqueous media. Mini-Rev. Org. Chem., 2013, 10, 207-216.

[124] Alza, E.; Sayalero, S.; Kasaplar, P.; Almași, D.; Pericàs, M. A Polystyrene-supported diarylprolinol ethers as highly efficient organocatalysts for Michael-type reactions. Chem. Eur. J., 2011 , 17, 11585-11595.

[125] Chuan, Y.; Chen, G.; Peng, Y. Highly enantioselective Michael addition reactions in water catalyzed by an insoluble MPS supported 4-sulfonamidyl prolinol tert-butyldiphenylsilyl ether. Tetrahedron Lett., 2009, 50, 3054-3058.

[126] Alza, E.; Cambeiro, X. C.; Jimeno, C.; Pericàs, M. A. Highly enantioselective Michael additions in wáter catalyzed by a PSsupported pyrrolidine. Org. Lett., 2007, 9, 3717-3720.

[127] Lombardo, M.; Chiarucci, M.; Quintavalla, A.; Trombini, C. Highly efficient ion-tagged catalyst for the enantioselective Michael addition of aldehydes to nitroalkenes. Adv. Synth. Catal., 2009, 351, 2801-2806.

[128] Luo, S.; Mi, X.; Liu, S.; Xu, H.; Cheng, J.-P. Surfactant-type asymmetric Michael addition to nitrostyrenes in water. Chem Commun., 2006, 3687-3689.

[129] Zheng, Z.; Perkins, B. L.; Ni, B. Diarylprolinol silyl ether salts as new, efficient, water-soluble, and recyclable organocatalysts for the asymmetric Michael addition on water. J. Am. Chem. Soc., 2010 132, 50-51.

[130] Qiao, Y.; He, J.; Ni, B.; Headley, A. D. Asymmetric Michael reaction of acetaldehyde with nitroolefins catalyzed by highly water-compatible organocatalysts in aqueous media. Adv. Synth. Catal., 2012, 354, 2849-2853.

[131] Tietze, L. F.; Brasche, G.; Gericke, K. M. Domino reactions in organic synthesis, Wiley-VCH, Weinhein, 2006.

[132] Enders, D.; Grondal C. Hüntl, M. R. M. Asymmetric organocatalytic domino reactions, Angew. Chem. Int. Ed., 2007, 46, 1570-1581.

[133] Guillena, G.; Ramón, D. J. Yus, M. Organocatalytic enantioselective multicomponent reactions (OEMCRs) Tetrahedron, 2007, 18, 693-700.

[134] Chintala, P.; Ghosh, S. K.; Long, E.; Headley, A. D.; Ni, B. The application of a recyclable organocatalytic system to the asymmetric domino Michael/Henry reaction in aqueous media. Adv. Synth. Catal., 2011, 353, 2905-2909.

[135] Sarkar, D.; Bhattarai, R.; Headley, A. D.; Ni, B. A novel organocatalytic system for the highly asymmetric Michael addition of aldehydes to nitroolefins in water. Synthesis, 2011, 1993-1997.

[136] Ghosh, S.; Qiao, Y.; Ni, B.; Headley, A. D. Asymmetric Michael reactions catalyzed by a highly efficient and recyclable quaternary ammonium ionic liquid-supported organocatalyst in aqueous media. Org. Biomol. Chem., 2013, 11, 1801-1804.

[137] Chen, Q; Qiao, Y.; Ni, B. Highly enantioselective organocatalytic Michael addition of ketones to nitroolefins in the presence of water. Synlett, 2013, 24, 839-842.

[138] Zu, L; Wang, J.; Li, H.; Wang, W. A recyclable fluorous $(S)$ pyrrolidine sulfonamide promoted direct, highly enantioselective Michael addition of ketones and aldehydes to nitrolefins in waster. Org. Lett., 2006, 8, 3077-3079.

[139] Zu, L.; Xie, H.; Wang, J.; Wang, W. Highly enantioselective aldol reactions catalyzed by recyclable fluorous $(S)$-pyrrolidine sulfonamide in waster. Org. Lett., 2008, 10, 1211-1214.

[140] Qiao, Y.; Headley, A. D. A simple and highly effective watercompatible organocatalytic system for asymmetric direct Michael reactions of linear aldehydes to maleimides. Green Chem., 2013 $15,2690-2694$

[141] Qiao, Y.; Chen, Q.; Lin, S.; Ni, B.; Headley, Organocatalystic direct asymmetric crossed-aldol reactions with acetaldehyde in aqueous media. J. Org. Chem., 2013, 78, 2693-2697.

[142] Ghosh, S. K.; Dhungana, K.; Headley, A. D.; Ni, B. Highly enantioselective and recyclable organocatalytic Michael addition of malonates to $\alpha, \beta$-unsaturated aldehydes in aqueous media. Org. Biomol. Chem., 2012, 10, 8322-8325.

[143] Ghosh, S. K.; Zheng, Z.; Ni, B. Highly active water-soluble and recyclable organocatalyst for the asymmetric 1,4-conjugate addition of nitroalkanes to $\alpha, \beta$-unsaturated aldehydes. Adv. Synth. Catal., 2010, 352, 2378-2382. 
[144] Akagawa, K.; Suzuki, R.; Kudo, K. Development of a peptidebased primary aminocatalyst with a helical structure. Asian J. Org. Chem., 2014, 3, 514-522.

[145] Maltsev, O. V.; Kucherenko, A. S.; Beletskaya, I. P.; Tartakovsky, V: A.; Zlotin, S. G.; Chiral ionic liquids bearing $O$-silylated $\alpha, \alpha-$ diphenyl $(S)$ - or $(R)$-prolinol units: recoverable organocatlysts for asymmetric Michale addition of nitroalkanes to $\alpha, \beta$-enals. Eur. $J$. Org. Chem., 2010, 2927-2933.

[146] Guillena, G.; Ramón, D. J.; Yus, M. Asymmetric organocatalyzed Morita-Baylis-Hillman reactions. Catalysis, 2012, 24, 223-252.

[147] Wei, Y.; Shi, M. Advances in Organocatalytic Asymmetric MoritaBaylis-Hillman/aza-Morita-Baylis-Hillman Reactions. Chem. Rev., 2013, 113, 6659-6690.

[148] Akagawa, K.; Sakamoto, S.; Kudo, K. Synthesis of indenes by intramolecular Morita-Baylis-Hillman reaction in aqueous media catalyzed by resin-supported proline. Synlett, 2011, 817-820.

[149] Marcia de Figueiredo, R.; Campagne, J.-M. In Comprehensive Enantioselective Organocatalysis: Catalysis, Reactions and Applications, Dalko, P. I. Wiley-VCH Verlag, Weinheim, 2013, Vol. III, pp 1043-1066.

[150] Bhadury, P. S.; Pang, J. Chiral Bronsted Acid-Catalyzed FriedelCrafts Reactions of Indoles. Curr. Org. Chem., 2014, 18, 21082120 .

[151] Akagawa, K.; Yamashita, T.; Sakamoto, S.; Kudo, K. FriedelCrafts-type alkylation in aqueous media using resin-supported peptide catalyst having polyleucine. Tetrahedron Lett., 2009, 50, 5602-5604.

[152] Akagawa, K.; Suzuki, R.; Kudo, K. Effect of the helical tether of a resin-supported peptide catalyst for the Friedel-Crafts-type alkylation in water. Adv. Synth. Catal., 2012, 354, 1280-1286.

[153] Akagawa, K.; Umezawa, R.; Kudo, K. Asymmetric one-pot sequential Friedel-Crafts-type and $\alpha$-oxyamination catalyzed by a peptide and an enzyme. Beilstein J. Org. Chem.. 2012, 8, 13331337.

[154] Du, H.; Ding, K. In Comprehensive Enantioselective Organocatalysis: Catalysis, Reactions and Applications, Dalko, P. I. Wiley-VCH Verlag, Weinheim, 2013, III, 1131-1162.

[155] Miller, J. P. Recent advances in asymmetric Diels-Alder reactions. Adv. Chem. Res., 2013, 18, 179-219.

[156] Park, J. K.; Sreekanth, P.; Kim. B. M. Recycling chiral imidazolidin-4-one catalyst for asymmetric Diels-Alder reactions: screening of various ionic liquids. Adv. Synth. Catal. 2004, 346, 4952.

[157] De Nino, A.; Bortolinio O.; Maiuolo, L.; Garofalo, A.; Russo, B.; Sindona, G. Tetrahedron Lett. 2011, 52, 1415-1417.

[158] Shen, Z.-L.; Cheong, H.-L.; Lai, Y.-C.; Loo, W.-Y.; Loh, T.-P. Application of recyclable ionic liquid-suuported imidazolidinone catalyst in enantioselective Diels-Alder reactions. Green Chem., 2012, 14, 2626-26-2630.
[159] Guizzetti, S.; Banaglia, M.; Siegel, J. S. Poly(methylhydrosiloxane)-supported chiral imidazolidinones: new versatile, highly efficient and recyclable organocatalysts for stereoselective Diels-Alder cycloaddition reactions. Chem. Commun., 2012, 48, 3188-3190.

[160] Ma, Y.; Jin, S.; Kan, Y.; Zhang, Y. J.; Zhang, W. Highly active asymmetric Diels-Alder reactions catalyzed by $C_{2}$-symmetric bypyrrolidines: catalyst recycling in water medium and insight into the catalytic mode. Tetrahedron, 2010, 66, 3849-3854.

[161] Davis, R. L.; Stiller, J.; Naicker, T.; Jiang, H.; Jørgensen, K. A Asymmetric organocatalytic epoxidations: reactions, scope, mechanisms and applications. Angew. Chem. Int. Ed., 2014, 53, 7406-7426.

[162] Juliá, S.; Masana, J.; Vega, J. C. "Synthetic Enzymes”. Highly Stereoselective Epoxidation of Chalcone in a Triphasic TolueneWater-Poly[$[(S)$-alanine] System. Angew. Chem. Int. Ed. Engl., 1980, 19, 929-931.

[163] Wennemers, H. Chem. Commun., 2011, 47, 12036-12041.

[164] Akagawa, K.; Kudo, K. Asymmetric epoxidation of $\alpha, \beta$ unsaturated aldehydes in aqueous media catalyzed by a resinsupported peptide containing unnatural amino acids. Adv. Synth. Catal., 2011, 353, 843-847.

[165] Li, J.; Hu, F.; Xie, X.-K. Liu, F.; Huang, Z.-Z. Synthesis of new functionalized chiral ionic liquid and its organocatlytic asymmetric epoxidation in water. Catal. Commun., 2009, 11, 276-279.

[166] Lv, J.; Wang, X.; Liu, J.; Zhang, L.; Wang, Y. Catalytic asymmetric epoxidation of chalcones under poly(ethylene glycol)supported Cinchona ammonium salt catalyzed conditions. Tetrahedron: Asymmetry, 2006, 17, 330-335.

[167] Akagawa, K.; Fujiwara, T.; Sakamoto, S.; Kudo, K. Efficient asymmetric $\alpha$-oxyamination of aldehydes by resin-supported peptide in aqueous media. Org. Lett., 2010, 12, 1804-1807.

[168] Akagawa, K.; Fujiwara, T.; Sakamoto, S.; Kudo, K. One-pot sequential alcohol oxidation and asymmetric $\alpha$-oxyamination in aqueous media using recyclable resin-supported peptide catalyst. Chem. Commun., 2010, 46, 8040-8042.

[169] Akagawa, K.; Kudo, K. A Peptide/Laccase cocatalyzed $\alpha$ oxyamination of aldehydes. Org. Lett., 2011, 13, 3498-3501.

[170] Akagawa, K.; Akabane, H.; Sakamoto, S.; Kudo, K. Organocatalytic asymmetric transfer hydrogenation in aqueous media using resin-supported peptide having a polyleucine tether Org. Lett., 2008, 10, 2035-2037.

[171] Akagawa, K.; Akabane, H.; Sakamoto, S.; Kudo, K. Asymmetric transfer hydrogenation in aqueous media catalyzed by resinsupported peptide having a polyleucine tether Tetrahedron: Asymmetry, 2009, 20, 461-466. 